\title{
An Ancient Model Organism to Test In Vivo Novel Functional Nanocrystals
}

\author{
Claudia Tortiglione \\ Istituto di Cibernetica "E. Caianiello", National Research Council of Italy, \\ Italy
}

\section{Introduction}

Scientific research largely depends on technological tools. If molecular biology allowed to manipulate the genome of complex organisms to investigate gene function, today nanotechnologies allow to synthesize objects at the same size scale as that of biological molecules, permitting the exploration of biological phenomena and dynamics at single molecule scale with unprecedented spatial precision and temporal resolution. Thanks to their superior physico-chemical and optoelectronic properties, colloidal semiconductor nanocrystals (NC), such as Quantum Dots (QD) and Quantum Rods (QR) have become attracting for investigators of different scientific fields. Their employment spans from electronics (tunable polarized lasers and organic-inorganic hybrid solar cells) (Hu et al., 2001; Huynh et al., 2002), to biology and medicine (biosensors, imaging and diagnostic contrast agents) (Alivisatos et al., 2005; Bruchez et al., 1998; Medintz et al., 2005). Recent advances in NC engineering, from synthesis to biofunctionalization, are being exploited to produce innovative nanodevices for drug delivery, gene silencing, hyperthermia treatments. However, their great potential to revolutionise basic and applied research founds its major concern in the lack of knowledge about their effects on biological systems, ranging from single cells to whole animals (Maynard et al., 2006). Nanocrystals size compares to that of biological molecules (nucleic acids, proteins, enzymes) and might interfere with the physiology/behaviour of the target living cell/animal, leading to unpredictable effects .

Among the factors to consider to predict the interaction of metal based nanocrystals with biological materials the core and the shell composition, the size and the surface charge of NC play crucial roles (Jiang et al., 2008). At the nanoscale, materials display properties profoundly different form their corresponding bulk chemicals, which may induce peculiar cellular responses, elicit several pathways of internalization, genetic networks, biochemical signalling cascades (Auffan et al., 2009; Choi et al., 2008; Demir E, 2010). The metal based core may adversely affect cell viability, unless properly shielded by surface coatings. Currently, increasing data addressing this important question relies on cell culture systems, and are focussed on the identification of the physicochemical parameters influencing the exposed cells (Hoshino and Yasuhara, 2004; Lewinski et al., 2008; Lovric et al., 2005b). Although cultured cells represent valid models to describe basic interactions with nanomaterials, they do not fulfil the in vivo response complexity.

It is a priority of the scientific community to evaluate the impact of novel nanostructrured materials in vivo, at level of whole animals (Fischer and Chan, 2007), and invertebrates 
represent valuable models for many reasons: they have a relatively short life span, with definite and reproducible staging for larval progression; the adult individual bodies are small and often transparent; the tests are quick, cost-effective and reproducible thanks to reliable standardized protocols, which makes them valuable systems for toxicity studies (Baun et al., 2008; Cattaneo, 2009).

In this chapter I will summarize some studies on the freshwater polyp Hydra vulgaris, a primitive organism at the base of metazoan evolution, to test NCs of different chemical composition, shell and surface coatings. The body structural complexity, simpler than vertebrates, with central nervous system and specialized organs, but much complex compared to cultured cells, makes Hydra comparable to a living tissue which cells and distant regions are physiologically connected. I will first generally describe the animal structural anatomy and physiology to allow non specialist readers to understand the mechanisms of tissue dynamics, reproduction, regeneration, on whose toxicity tests are relied. In the following sections I will describe the elicitation of different behaviours, internalization routes, toxicity effects, in response to different NCs, highlighting the advantages of using Hydra for fast, reliable assays of NC effect at whole animal level. Through the description of our studies using functionalized CdSe/ZnS QDs, unfunctionalized CdSe/CdS QRs, ultrasmall CdTe QDs, I will show that Hydra, up to now used mainly by a niche of biologists to study developmental and regeneration processes, have great potential to inspire scientists working in field of nanoscience, from chemists to toxicologists demanding new models to assess nanoparticle impact on human health and environment (Fischer and Chan, 2007), and to decipher the molecular basis of the bio-non bio interaction.

I would like to point out that all the data described in this chapter result from the interdisciplinary work with researchers in the field of nanomaterial science, which I sincerely thank. The continuous discussions and knowledge's exchanges between the different disciplines (chemistry, material science, biology, physiology), hided beyond each study, laid the foundations of an interdisciplinary platform for the smart design, testing and safe assessment of novel nanomaterials.

\section{Hydra vulgaris: An ancient model system}

Hydra belongs to the animal phylum Cnidaria that arose almost 600 million years ago (Lenhoff et al., 1968). Its body plan is very simple, consisting of a single oral-aboral axis with radial symmetry. The structures along the axis are a head, a body column and a foot to anchor to a substrate. The body has a bilayered structure, made of two unicellular sheets (ectoderm and endoderm) continuously dividing and migrating towards the animal oral and aboral extremities to be sloughed off. A third cell lineage, the interstitial stem cells lineage, is located in the interstices, among the epithelial cells of both layers (Fig. 1). These interstitial cells are multipotent stem cells that give rise to differentiated products: neurons, secretory cells, gametes, and nematocytes, phylum- specific mechano-sensory cells that resemble the bilaterian mechano-sensory cells in virtue of their cnidocil. Upon stimulation this cnidocil leads to the external discharge of an intracellular venom capsule (the nematocyst or cnidocyst), involved in the prey capture. Despite the simplicity of its nervous system, organized as a mesh-like network of neurons extending throughout the animal, the complexity of the mechanisms underlying neurotransmission resemble those of higher vertebrates, including both classical and peptidergic neurotransmitters (Pierobon et al., 2001; Pierobon et al., 2004). This makes Hydra an ideal system to study the behavioural response of a whole animal to an external stimuli, i.e. bioactive nanomaterials. 


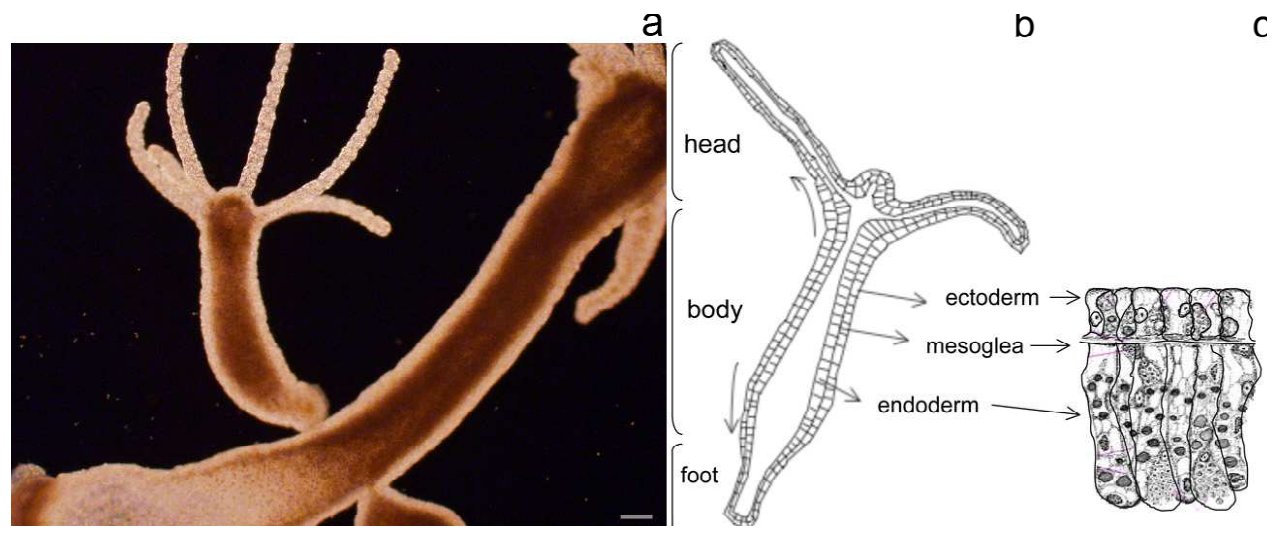

Fig. 1. Anatomical structure of Hydra vulgaris

Picture of living Hydra. a) The animal is shaped as a hollow tube with a head at the apical end, and a foot, or basal disc at the other. The head is in two parts, the hypostome (mouth) at the apex, and below that the tentacle zone from which a ring of six-eight tentacles emerges. The picture shows an adult animal with two buds emerging from the gastric region, facing two opposite parts. Scale bar $100 \mu \mathrm{m}$. b) Schematic representation of the bilayered structure of the animal: the body wall is composed of two self renewing cell layers, an outer ectoderm and an inner endoderm, separated by an extracellular matrix, the mesoglea. The arrows on the left side indicate the direction of tissue displacement. c) Along the animal body both ectoderm and endoderm layers are composed of epitheliomuscular cells, while interstitial stem cells and their intermediate and terminal derivatives (neurons, nematocytes and secretory cells) are interspersed among the two layers. Modified from (Tino, 2011).

Hydra polyps reproduce both sexually and asexually. Massive culturing is achieved thanks to fast mitotic reproduction, warranting a large number of identical clones (Loomis, 1956). The epithelial cells structuring the body continuously divide and contribute to the formation of new individuals, budding from the gastric region, and detaching from the mother in about 3 days (Figure 1A) (Galliot et al., 2006). Growth rate of Hydra tissue is normally regulated by a balance between epithelial cell cycle length, phagocytosis of ectodermal cell in "excess", and bud formation (Bosch and David, 1984). Environmental factors, such as the presence of pollutants or the feeding regime, can affect this balance. Thus, the population growth rate is an indirect measure of the Hydra tissue growth rate and cell viability.

Another peculiar feature of Hydra physiology is the remarkable capacity to regenerate amputated body parts. Polyps bisection at gastric or subhypostomal level in two parts generates stumps able to regenerate the missing parts (see Figure 2). Morphogenetic processes take place during the first $48 \mathrm{~h}$ post amputation (p.a.), followed by cell proliferation to restore adult size (Bode, 2003; Holstein et al., 2003). This highly controlled process relies on the spatiotemporal activation of specific genes and is object of wide investigations (Galliot and Ghila, 2010; Galliot et al., 2006). Moreover it can be adversely affected by the presence of organic and inorganic pollutants and specific assays have been developed to quantify this effect (Karntanut and Pascoe, 2000; Pollino and Holdway, 1999; Wilby, 1990).

Hydra is very sensitive to environmental toxicants and it has been used as biological indicator of water pollution. The responsiveness to different environmental stressors varies 
among different species, but it is always quantifiable by standardized protocols in terms of median lethal concentration and median lethal time (LC50 and LT50). For this reason short term (lethality) and long-term (sub-lethality) tests based on the evaluation of polyp morphology, reproductive activity and regeneration efficiency, can be used to test the potential toxicity/teratogenic effect of any kind of medium suspended compound.

Beside the effects detectable at macroscopic level, the availability of the genome sequence makes it possible to study the molecular mechanisms and gene pathways activated by the addition of external (chemical or physical) stressors. One of the main outcomes of the genomic sequencing projects of cnidarian species (corals, anemones, jellyfish and Hydras) (Chapman et al., 2010; Putnam et al., 2007) is the recognition that many genes, including those associated with diseases, are conserved in evolution from yeast to man (Steele et al., 2011). Remarkably, a surprisingly complexity was found in cnidarian genomes, in the range of higher vertebrates, while other invertebrates routinely used as model organisms, such as the fruit fly Drosophila melanogaster or the flatworm Caernorabditis elegans, have lost during speciation many genes belonging to the common eumetazoan primitive ancestor. In Hydra, the key pathways underlying development, regeneration and re-aggregation have been identified and their characterization showed the presence of almost complete gene repertoires: the canonical and non canonical Wnt pathways for maintaining and re-establishing apical organizer activity and for cellular evagination processes, respectively; the BMP/chordin pathway for axis patterning; the MAPK- CREB pathway for head regeneration; the FGF pathway for bud detachment, and the Notch pathway for differentiating some interstitial cell lineages (reviewed by Galliot, 2010; Galliot and Ghila, 2010).

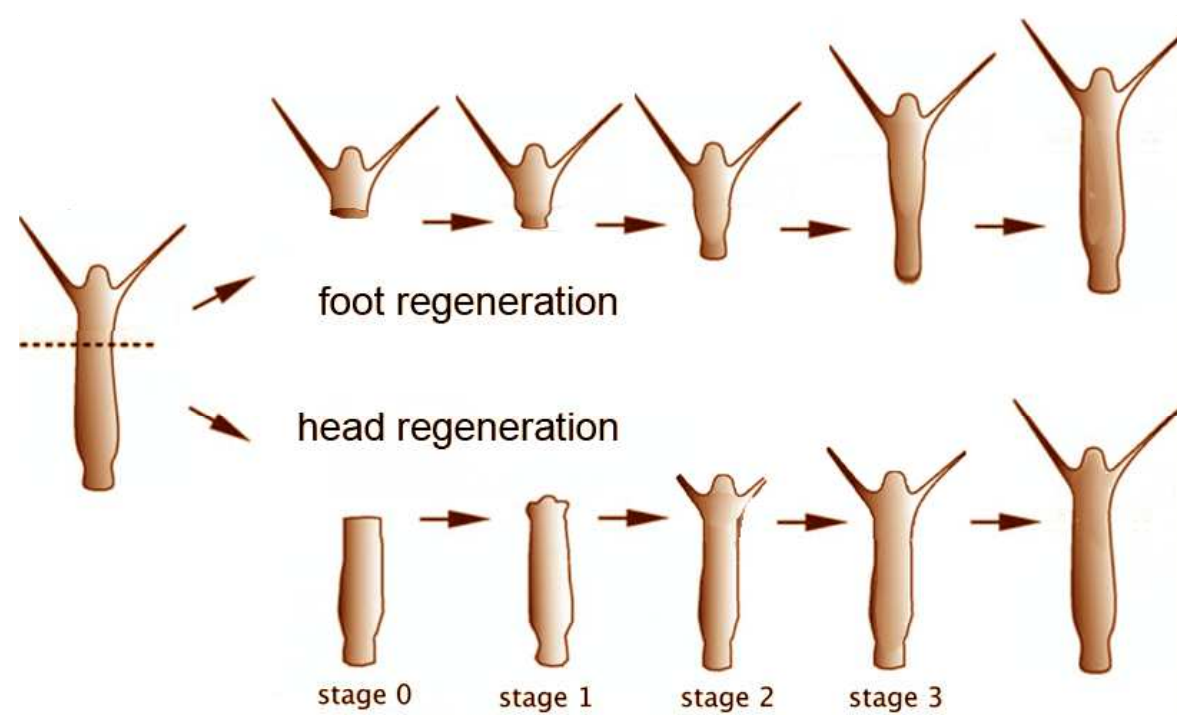

Fig. 2. The regeneration process in Hydra vulgaris

Hydra body column has a high capacity for regeneration of both the head and foot. Because of the tissue dynamics that take place in adult Hydra, the processes governing axial patterning are continuously active to maintain the form of the animal. Following amputation at mid-gastric level, the two polyp halves immediately initiate an asymmetric process at the wound site: the 
upper half undergoes foot regeneration in about two days, whereas the lower half initiates the head regeneration process, which is completed in three days. Biochemical, cellular and molecular analyses showed that these two regions immediately undergo different reorganization to become foot and head regenerating tips, respectively. Cell proliferation and differentiation during the late stages allow adult size to be restored.

\section{In vivo interactions between semiconductor nanocrystals and Hydra}

\subsection{GSH functionalized QDs target specific cell types in Hydra}

The tripeptide glutathione (g-L-glutamyl-L-cysteinylglycine, GSH) has been well-known to biochemists for generations. Both the reduced form (GSH) and its oxidized dimer (GSSG) have been implicated in a variety of molecular reactions throughout the animal kingdom. Although it is best known for its role as a free radical scavenger, GSH also performs a number of other functions in cell survival and metabolism, including amino acid transport, detoxification of xenobiotics, maintenance of protein redox state, neuromodulation, and neurotransmission. Almost 50 years ago, Loomis and Lenhoff suggested a role of GSH in signal transduction in Hydra (Loomis, 1955). A class of binding sites for GSH has been described (Bellis et al., 1994; Grosvenor et al., 1992), providing the basis for the behavioural response. However, up today, the GSH receptors have not been isolated. With the aim to identify in vivo GSH receptor/binding proteins we synthesized GSH functionalized fluorescent semiconductor quantum dots and analysed in vivo the elicitation of a behavioural response together with the localization of GSH targeted cells (Tortiglione et al., 2007). The choice of QD arose from the great advantages offered by these new nanotechnological probes over conventional ones which are revolutionising biology and medicine (Medintz et al., 2005). Colloidal semiconductor QD probes have unique photophysical properties, such as size-tuneable emission spectrum, narrow emission peak, broad absorption profile, and high brightness; they are much more stable to the permanent loss of fluorescence than conventional organic fluorophores (Michalet et al., 2005) becoming powerful investigation tools for multicolour, long-term, and high-sensitivity fluorescence imaging. QD functionalization with GSH was obtained by several reaction steps: core/shell CdSe/ZnS QDs were first water solubilized by the addition of an amphiphilic polymer coating (PC), then stabilized by Polyethylene Glycole (PEG) molecules, and finally covalently bound to GSH (Figure 3).
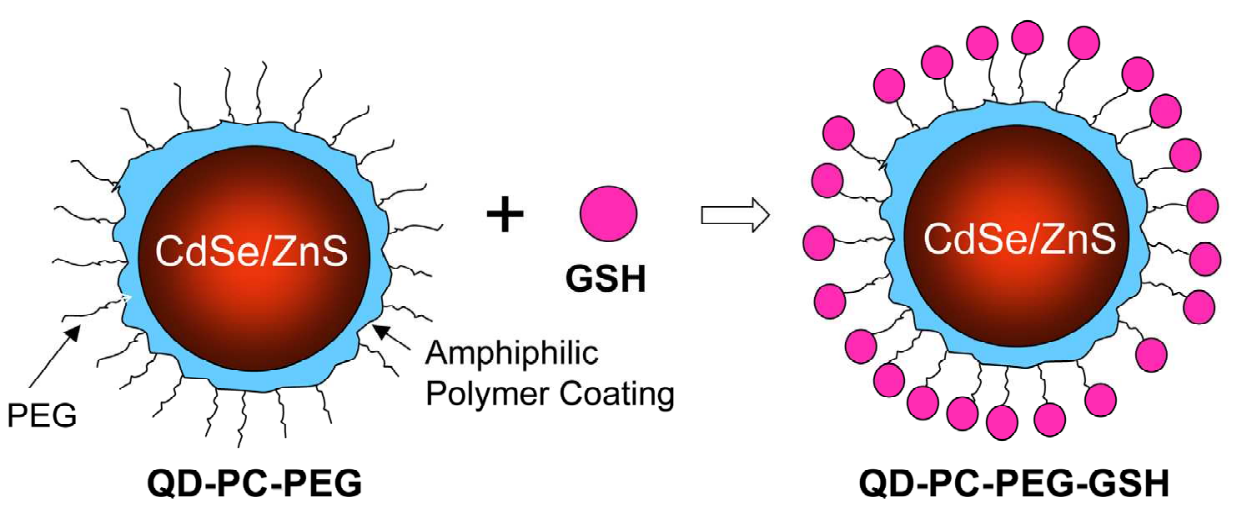

Fig. 3. Schematic representation of a GSH-QD conjugate. 
Polymer-coated CdSe/ZnS core shell quantum dots were first conjugated to diaminomodified PEG molecules and then to GSH through amide bond formation. The resulting bioconjugated were extensively characterized to confirm the presence of the surface functionalizations (Tortiglione et al., 2007).

Both PEG-QDs and PEG-GSH-QDs were supplied to living polyps at different concentrations and then observed by fluorescence microscopy. A biological response consisting in mouth opening and QD entry into the gastric cavity was elicited by GSH-QDs. The elicitation of this behaviour, although slightly different from the classical feeding response (consisting of tentacle writhing and mouth opening) and occurring in a small percentage of animals (15\%), was specific for GSH coated QDs, and indicated the bioactivity of the new GSH abduct. Fluorescent QD targeted cells were found within the inner endodermal cells, which internalized the QD upon mouth opening (see Figure 4) (Tortiglione et al., 2007).

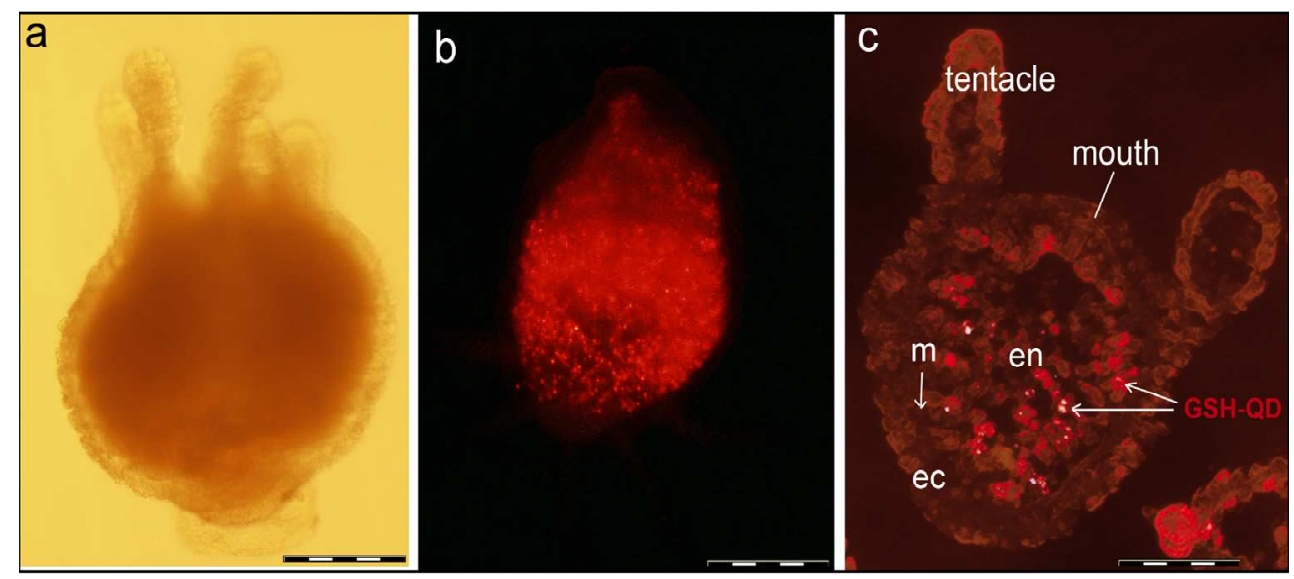

Fig. 4. In vivo fluorescence imaging of Hydra polyps treated with $300 \mathrm{nM}$ GSH-QDs (emission max: $610 \mathrm{~nm}$ ).

a) Bright field image of Hydra treated with GSH-QDs showing animal basic structure. The foot is on the lower part of the panel, while a crown of tentacles surrounds the mouth. b) Image taken $24 \mathrm{~h}$ after treatment: an intense fluorescence is distributed all along the gastric region. c) Cellular localization of QDs in Hydra cross sections. The whole Hydra was treated with $300 \mathrm{nM}$ GSH-QDs for $24 \mathrm{~h}$, fixed in $4 \%$ paraformaldehyde, and included for cryosectioning. Images were collected using an inverted microscope (Axiovert, 100, Zeiss) equipped with fluorescence filter sets (BP450-490/FT510/LP515). Endodermal cells(en) are separated from ectodermal cells (ec) by an extracellular matrix, the mesoglea $(\mathrm{m})$, indicated by the arrow. Red fluorescence corresponds to GSH-QDs located specifically into endodermal cells. Scale bars: $500 \mu \mathrm{m}$ in a, b; $200 \mu \mathrm{m}$ in c

The fluorescence pattern and intensity lasted unaltered until the animals were fed again, after which the signal started to fade slowly and was diluted throughout the emerging buds (Figure 5). 

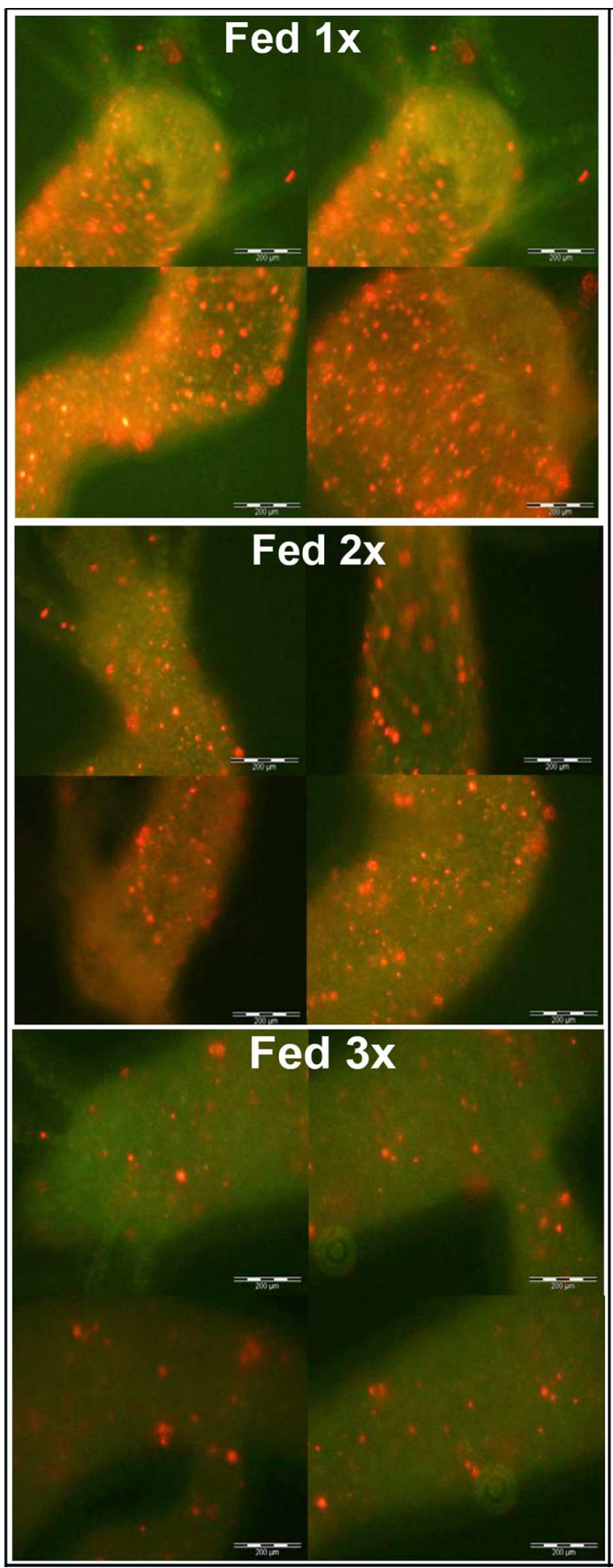

Fig. 5. Tracking QD fluorescence under normal feeding regime 
GSH-QDs do not undergo degradation into the endodermal cells. They follow cell turnover and migration towards the animal ends and the developing bud. Hydra treated with GSHQDs were fed on alternate days. After three feeding cycles GSH-QDs were found diluted among the endodermal cells, continuously diving. The orange fluorescent punctuated pattern decreases uniformly as new buds are formed on the mother (see lower panel, representing an adult with an emerging bud). Scale bars are $200 \mu \mathrm{m}$ in all pictures.

The uptake of GSH-QDs was an active endocytotic process, as shown by its inhibition when performing the incubation at $4{ }^{\circ} \mathrm{C}$. Tissue cryosection and dissociation of whole treated polyps into single cell suspensions confirmed the presence of QDs into cytoplasmic granular vesicles. In conclusion this first work showed that GSH-QDs alone can stimulate a response, although in a small percentage $(15 \%)$ of the treated animals. Possible reasons for this low percentage could be a low concentration of the GSH molecules conjugated to the QD surface or the modified stereochemical conformation of the bound GSH molecules, which does not allow for correct interaction with the protein target. Although the bioactive GSH-QDs could target specific cells, as shown by the fluorescence of the endodermal layer, the nature of the GSH binding protein (as GSH receptor, GSH transporters...) remain to be determined. An important clue emerged from this study was the capability of PEG-QDs to be also internalized by endodermal cells, upong chemical induction of mouth opening. The uptake rate was lower compared to GSH-QDs, indicating different internalization routes and underlying mechanism for the two types of QDs. Considering the multiple roles played by glutathione in metabolic functions, and in particular in the nervous system of higher vertebrates, GSH functionalized nanocrystals prepared and tested in this work represent promising tools for a wide variety of investigations, such as the elucidation of the role played by GSH in neurotransmission and the identification of its putative receptor. Beside these considerations, the capability of PEG-QDs to be up taken by Hydra cells prompted us to investigate more in detail the mechanism of internalization of QDs, the role played by the surface ligand, the surface chemistry and charge, which underlies any bio-non -bio interaction.

\subsection{Unfunctionalized Quantum Rods elicit a behavioural response in Hydra vulgaris}

The capability of Hydra to internalize, upon chemical induction of mouth opening, PEG-QDs into endodermal cells suggested that also unfunctionalized nanocrystals can play active roles when interacting with living cells. Noteworthy attention should be paid to the chemical composition of surfactant-polymer-coated nanoparticles not only in determining their stability in aqueous media but also in investigating their interaction with cells and intracellular localization. With the aim to test the impact of a new kind of semiconductor nanocrystal on Hydra vulgaris, we demonstrated that specific behaviours might be induced by exposure of whole animals to unfunctionalized nanocrystals and that a careful investigation of the impact of the new material on living cells must be carried out before designing any nanodevice for biomedical purposes (Malvindi et al., 2008).

The nanocrystals under investigation were fluorescent CdSe/CdS quantum rods (from here named QRs). In addition to QD properties, such as bright photoluminescence (PL), narrow emission spectra, and broad UV excitation, QRs have larger absorption cross-sections, which might allow improvement to certain biological applications where extremely high brightness and photostability are required. QRs of length and diameter $35 \pm 2 \mathrm{~nm}$ and $4.2 \pm$ $0.4 \mathrm{~nm}$, respectively, were synthesised according to a newly developed procedure (Carbone et al., 2007), and transferred to aqueous medium by using the same methodology described above for QDs (Pellegrino, 2004; Sperling, 2006; Williams, 1981). The resulting highly 
fluorescent PEG coated QRs (Figure 6) were challenged to living polyps, which were monitored over progressive incubation periods.
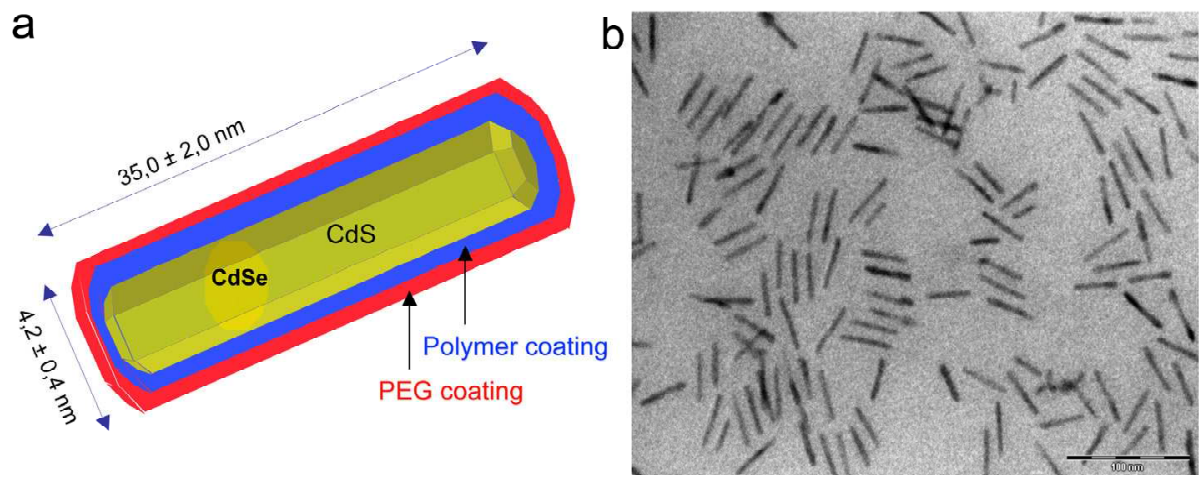

Fig. 6. A schematic representation of the CdSe/CdS rods used in this study

The scheme shows the asymmetrical shape derived from the synthesis procedure (Carbone et al, 2007). The method involves coinjecting $\mathrm{Cd}^{2+}$ and $\mathrm{S}^{2-}$ precursors and preformed spherical CdSe seeds into an environment of hot surfactants, well suited for the anisotropic growth of the second shell-material (CdS) on the first underlying core (CdSe). Resulting QRs are transferred from chloroform to water by wrapping them within an amphiphilic polymer shell (blue shell in the figure). To these polymer-coated QRs, polyethylene glycol (PEG) molecules (red shell) can be bound by using an EDC catalyzed cross linking scheme. The rod samples are an average of $35 \mathrm{~nm}$ in length and $4 \mathrm{~nm}$ in diameter as confirmed by b) the TEM image of the corresponding sample (generously provided by Dr.A.Quarta, Italian Institute of Technology, Lecce, Italy)

Unlabelled cells were detectable by fluorescence microscopy, indicating that QRs were not uptaken by Hydra ectodermal cells. However, an unexpected animal behaviour was observed which consisted of an intense tentacle writhing, i.e. contractions and bending along the axial length of each tentacle, as shown in Figure 7.

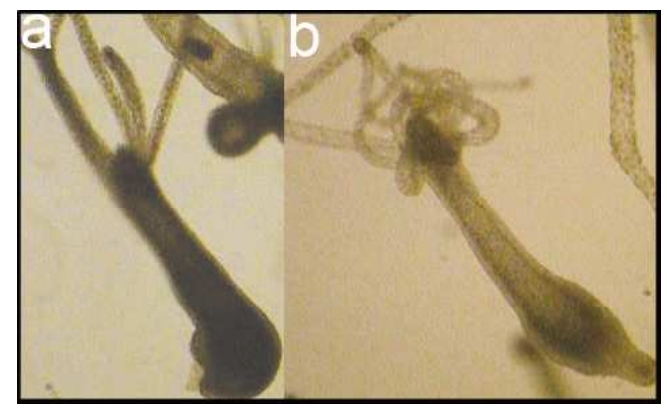

Fig. 7. Elicitation of tentacle writhing by QRs.

The test was initiated by adding CdSe/CdS core/shell QRs to each well containing six polyps and motor activity was monitored by continuous video recording using a Camediadigital camera (Olympus) connected to a cold light Wild stereo microscope a) Hydra polyp 
in physiological condition show extended tentacles. b) Within seconds of addition of QRs to the culture medium the polyp's tentacle begin to writhe, bending toward the mouth. Contractions are not synchronous for all tentacles and lasted for an average of ten minutes (Malvindi et al., 2008).

The elicitation of this behaviour over an average period of ten minutes was dependent on the presence of calcium ions into Hydra medium, as shown by the inhibition of such activity by the calcium chelator EGTA. Interestingly, Hydra chemically depleted of neuronal cells were unresponsive to QRs, indicating that excitable cells are targeted by QRs. The mechanisms underlying neuron excitation are still under investigation, but the shape anisotropy has been shown involved in the elicitation of the activity, as nanocrystals of the identical chemical composition, but shaped as dots were ineffective. We suggested that CdSe/CdS QRs, regardless of surface chemical functionalization, may generate local electric fields associated with their permanent dipole moments that are intense enough to stimulate voltage dependent ion channels, thus eliciting an action potential resulting in motor activity. Results from a geometrical approximation (Malvindi et al., 2008) showed that a QR voltage potential of sufficient intensity to stimulate a voltage gated ion channel can be produced at nanometric separation distances, i.e. those lying between cell membranes and medium suspended QR, regardless of its orientation at the cell surface, thus it is theoretically possible for QRs to elicit neuronal activity. This hypothesis is currently under investigation in vertebrate model systems. In particular, we have preliminary data on the modulation of the electrophysiological properties of mammalian brain slices by QRs, (unpublished data) which indicate that QR response is not specific to our experimental model. Considering the challenges encountered in the design and synthesis of electrical nanodevices for neuronal stimulation (Pappas, 2007) we propose biocompatible, soluble QRs as a novel resource for neuronal devices, for diagnostic and therapeutic applications where non invasive probing and fine tuning of neuronal activity is required.

The peculiarities of our biological model system, such as the low-ionic-strength culture media and the presence of excitable cells directly facing the outer media, allowed us to highlight the neuronal stimulation by a nanometric inorganic particle, which might be difficult to study in vivo in a more complex whole organism. Avoiding the difficulties in investigating vertebrate brain behaviour in vivo, our cnidarian model organisms provided a simple, reliable, and fast system for screening nanoparticle activity in vivo on a functionally connected nerve net.

\subsection{Unfunctionalized Quantum Rods reveals regulated portal of entry into Hydra cells}

The complexity of the molecular interactions underlying the endocytosis suggests that a great evolutionary effort has been spent to regulate the cellular response to a variety of different environmental stimuli. In multicellular organisms the endocytic and secretory pathways evolved to control all aspects of cell physiology and intercellular communication (neurotransmission, immune response, development, hormone-mediated signal transduction). In this scenario, the emerging nanomaterials, variable in size (from 2 to 100 $\mathrm{nm}$ ), chemical composition (gold, cadmium telluride, cadmium selenide, iron oxide) and physical properties (charge, spectral profile, colloidal stability, magnetism) represent a new class of compounds interacting with biological systems, which underlying mechanisms need to be carefully investigated. When studying the impact of CdSe/CdS QRs on Hydra (Malvindi et al., 2008), beside the detection of a specific behavioural response, an accurate microscopy analysis was performed in order to assess the putative internalization of the 
QRs into Hydra cells. At neutral $\mathrm{pH}, \mathrm{QR}$ uptake was never detectable at the concentrations $(7 \mathrm{nM})$ eliciting biological activity. By contrast, using the same concentration of CdSe/CdS QRs, but changing the $\mathrm{pH}$ of the Hydra medium toward mild acidic values ( $\mathrm{pH} 4.5-4$ ), an intense fluorescence was observed (Tortiglione et al., 2009). The labelling pattern as soon as 30 minutes post incubation with QRs appeared like a uniform red fluorescence staining all around the animal (Figure 8a). In the following hours membrane bound nanocrystals appeared compacted within cytoplasmic granular structures, easily detectable as red spots at level of the tentacles first (Figure 8b), and then throughout the body (Figure 8c).

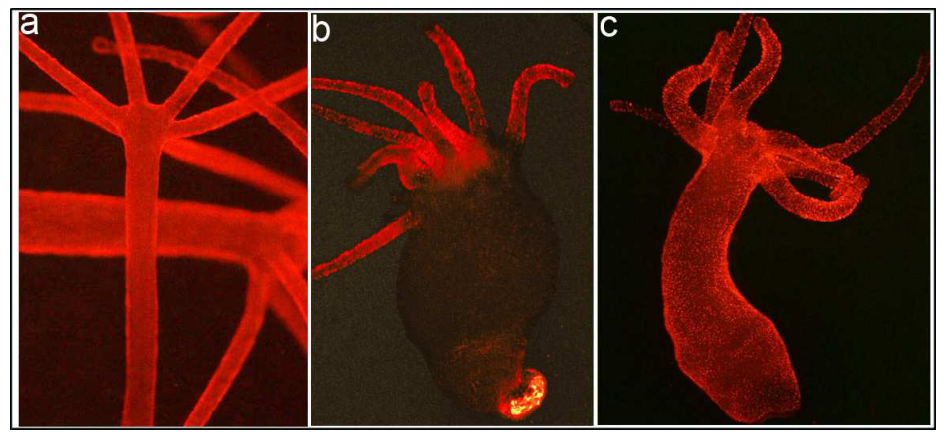

Fig. 8. In vivo fluorescence imaging of Hydra vulgaris exposed to QRs for different periods a) In vivo image of two Hydra, 30 minutes post incubation (p.i.): QR red fluorescence labels uniformly all body regions. A second Hydra is placed horizontally below b) In vivo image of a polyp $2 \mathrm{~h}$ p.i. with QRs. A strong punctuated fluorescence labels the mouth, the tentacles and at a lower extent the animal body. c) Later on, in most of the animals, the punctuated fluorescence is evident also in body column.

Tissue cryosections made from treated animals allowed to detect not only the ectodermal localization of the internalized QRs, but also the dynamic of the labelled cells, at various time after incubation (Figure 9).
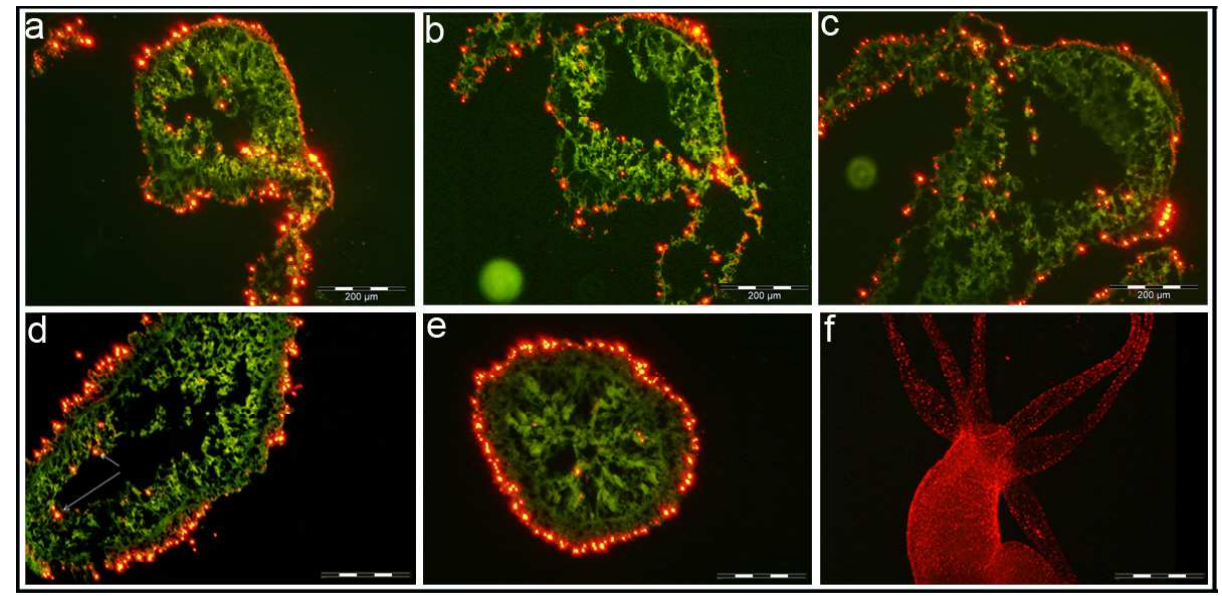

Fig. 9. Tissue localization of QRs in Hydra tissue sections. 
Intact Hydra were treated with QRs at acidic $\mathrm{pH}$ for $4 \mathrm{~h}$, and $24 \mathrm{~h}$ later fixed and processed for cryosectioning. The green colour is due to tissue autofluorescence, while the red staining indicate the QR presence. Serial longitudinal tissue cryosections obtained at level of the head ( $a, b$ and $c$ ) and body (d) show QRs located into the ectodermal cells, but also inside endodermal cells lining both the tentacles and gastric region. A transversal section (e) confirms the tissue distribution. The labelling pattern before sectioning is shown in (f). Scale bars: $200 \mu \mathrm{m}$ (a-e), and $500 \mu \mathrm{m}$ (f).

Remarkably, $24 \mathrm{~h}$ post treatment, fluorescent material appeared also into the endodermal cells lining the gastric cavity and the tentacles. At the tentacle base, the fluorescence draws a well defined strip along the tentacle length, shown by cross sections to be localised inside the endodermal cells and not in the tentacle lumen (Figure 9a, 9b, 9c). This cell dynamic, from ectoderm to endoderm, has never been described using conventional organic fluorophores and highlights the importance of using the innovative fluorophore to probe biological processes. The high photostability of the QRs allowed to study with unprecedented brightness and resolution endocytotic processes in Hydra and to track these phenomena over long periods. The same dynamic was observed also during regeneration of treated animals and it probably depends from autophagocytosis process occurring during head regeneration (Tortiglione et al., 2009). Beside these results, we determined the factors involved in the capability of Hydra to uptake QRs at acidic but not neutral $\mathrm{pH}$ and investigated the roles played by the nanocrystal surface at one side and by Hydra membranes at the other. QRs used in this study where stabilised by the addition of aminoPEG coating. Zeta potential measurement showed that at acidic $\mathrm{pH}$ QRs were positively charged, while at neutral $\mathrm{pH}$ their surface net charge was neutral or negative. Modifying the amounts of amino-PEG molecules present on QR surface we were able to tune the QR net charge and thus the up taking process. At acidic $\mathrm{pH}$, the protonation of the PEG amino terminal groups $\left(\mathrm{NH}^{3+}\right)$ contributes to increase the positive charges while the protonation of the carboxyl groups of the amphiphilic polymer shell causes a reduction of the negative charges ( $\left.\mathrm{COO}^{2}-\right)$ at the nanoparticle surface and indeed the sum of the two effects results in a net positive surface of the QR (Figure 10). The different amounts of PEG molecules attached at the same QR surface account for the different behaviours displayed by diverse nanorod samples, independently from their size and shape. QRs presenting positive zeta potential bind to negatively charged membrane lipids, and stimulate endocytosis processes. A scheme of the QR protonation occurring at acidic $\mathrm{pH}$ is shown in Figure 10.

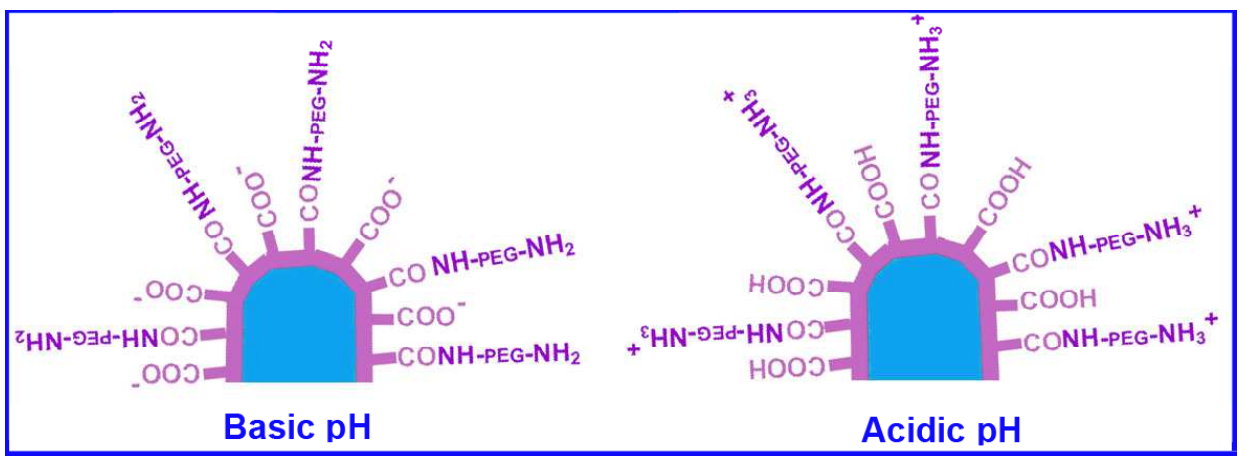

Fig. 10. Protonation/de-protonation state of the QRs. 
A schematic view of the functional groups at the nanoparticle surface responsible for the switching of the surface charge. At basic $\mathrm{pH}$, the carboxy groups are negatively charged and the amino groups are not protonated. At acidic $\mathrm{pH}$, the carboxy and the amino groups are both protonated, which account for a positive zeta potential value measured. At neutral $\mathrm{pH}$, the zeta potential measured in all cases is negative. The blue colour indicates the CdS/CdS core, while the amphiphilic polymer and PEG coatings are pink coloured. Modified from (Tortiglione et al., 2009).

We also investigated the biological factors involved in the internalization of QRs at acidic $\mathrm{pH}$, and found the involvement of a peculiar protein displaying a $\mathrm{pH}$ dependent behaviour, named Annexin (ANX) (Moss and Morgan, 2004). ANXB12 is a Hydra protein belonging to the annexins superfamily, able to insert into lipidic membranes and to form ion channels at acidic but not neutral pH (Schlaepfer et al., 1992a; Schlaepfer et al., 1992b). As Hydra treatment with anti-ANX antibody prevented QR uptake, we suggest that ANX mediates the interaction with positively charged QRs, organizing membrane domains and uptake processes, probably throughout the specie-specific amino terminal domain. In presence of anti-ANX antibody, the endocytosis machinery is blocked, likely due to impairment of functional or structural important ANX extracellular domains.

In conclusion, the combined effect of nanorod positive surface charge and structural properties of cell membranes, at acidic $\mathrm{pH}$, resulted in the active internalization of the fluorescent nanoparticles into specific cell types and according to a precise temporal dynamic. The availability of beautifully illuminated animals led to track fluorescent cells during developmental and regeneration processes, and to describe, beside known migration events, new cell dynamics and inter-epithelial/intercellular trafficking phenomena, which intriguing meaning lays the foundations for further investigations. Thus, we provide an example of how, probing cell and animal biology with nanosized compounds, we can uncover novel biological phenomena, aware of our capability of finely tuning and controlling this interaction for specific purposes.

The two examples of Hydra/QR interaction described in the two sections above show two biologically relevant responses induced by the same nanocrystal, determined in one case by the QR intrinsic shape dependent electrical properties, and in the other one by the QR positive surface charge. These studies show that presentation of chemical information at the same size scale as that of cell surface receptors may interfere with cellular processes, eliciting unexpected responses, such as the activation of a behavioural responses, or cell uptake, and that a simple experimental change, such as the $\mathrm{pH}$ of the medium used in the bioassay, may determinate dramatic difference in the evoked response. Thus, the interactions occurring at the interface bio-non bio are complex and depending on both players, which need to be fully characterized when designing nanodevices targeting biological systems.

\subsection{Cadmium telluride QDs induce cytotoxic effects in Hydra vulgaris}

The freedom to design and modify NCs to accomplish very specific tasks is currently being realized. However, their unique properties, not present in conventional bulk materials, such as enhanced magnetic, electrical and optical properties, have potential implications in NC toxicity, such as elemental composition, charge, shape, surface area and surface chemistry/derivatization. Several data of the inherent toxicity of some NCs are available and indicate that they can affect biological behaviour at the organ, tissue and cellular levels, and activate changes in the expression of stress-related or apoptotic 
genes (Choi et al., 2008; Rivera Gil et al., 2010). The great amount of data collected up to today regards different materials, biological systems, and are strictly dependent on the cell lines tested (Lewinski et al., 2008). This may be a result of interference with the chemical probes, differences in the innate response of particular cell types, as well as depending upon the different protocols used by different laboratories for the nanoparticle synthesis and characterization, giving rise to not identical nanomaterials. Therefore, for a single nanocrystal, the biological activities of NCs should be assessed by multiple cell-based assays and should more realistically rely on animal models (Fischer and Chan, 2007).

A primary source of QD toxicity results from cadmium residing in the QD core. Toxicity of uncoated core CdSe or CdTe-QD has been discussed in several reports and is associated, in part, with free cadmium present in the particle suspensions or released from the particle core intracellularly (Derfus, 2004; Kirchner et al., 2005; Lovric et al., 2005a). Free radical formation induced by the highly reactive QD core might also play crucial roles in the cellular toxicity. Encapsulation of the CdSe-QD with a ZnS shell or other capping materials has been shown to reduce toxicity, although much work remains to be completed in this field. However, to accurately assess safety of shell or capped particles, the degradation of the shell or capping material, along with its cytotoxicity must also be considered since several groups have found increased toxicity associated to capping materials such as mercaptoacetic acid and Topo-tri-n-octylphosphine oxide (TOPO) (Smith et al., 2008). Taken together, these reports suggest that the integrity of shell and capping materials, as well as toxicity, needs to also be more thoroughly assessed and that shell/capping materials must be assessed for different QD preparations.

Based on these considerations long term studies of effects on both cell viability and signal transduction are needed, and surely the animal studies are definitely required for proper assessment of QD toxicity. To date, rats have been used as model organisms for pharmacological studies, and only recently the use of invertebrates to test $\mathrm{Cd}$ based QDs is adding valuable informations in this field. For example, the freshwater macroinvertebrate, Daphnia magna, has been used to evaluate toxicity characteristics of CdSe/ZnSe in relation to surface coatings (Lee, 2009).

Cnidaria are sensitive to many environmental stressors and may become valuable indicators of exposure to disruptive chemicals and other stressors, such as nanomaterials. During animal evolution, an array of gene families and pathways (also known as "environmental genes") have evolved to face physical, chemical, and biological stressors. While the immune system responds to biotic stressors such as pathogens (Miller et al., 2007), another set of genes named "chemical defensome" (Goldstone, 2008), has been identified to sense, transform, and eliminate potentially toxic chemicals.

Hydra is sensitive to a range of pollutants and has been used to tests on water contamination by heavy metals (Holdway et al., 2001; Pascoe et al., 2003; Pollino and Holdway, 1999). Metal pollutants such as copper, cadmium and zinc have been tested against different Hydra species, and the relative toxicity based on the median lethal concentration (LC50) for all species was ranked from copper, the most toxic, to cadmium, with zinc least toxic (Karntanut and Pascoe, 2002; Karntanut and Pascoe, 2005). Drugs and pharmaceuticals targeted at mammalian receptors have also been shown to adversely affects Hydra (Pascoe et al., 2002), showing the feasibility to use this aquatic invertebrate to accurately assess the potential toxicological effect of any kind of molecule added to the animal culture medium. 
In light of this knowledge we evaluated the possibility to use Hydra for nanotoxicology purposes. We addressed the toxicological effects of fluorescent CdTe QDs, presenting different chemical coatings on Hydra using several bioassays: 1) alteration of morphological traits, measurable as morphological median score values 2) alteration of reproductive capabilities, measurable as population growth rates 3) alteration of regeneration or pattern formation. These three phenomena are schematically drawn in Figure 11.

Morphological alteration

Reproductive capabilities $\rightarrow$

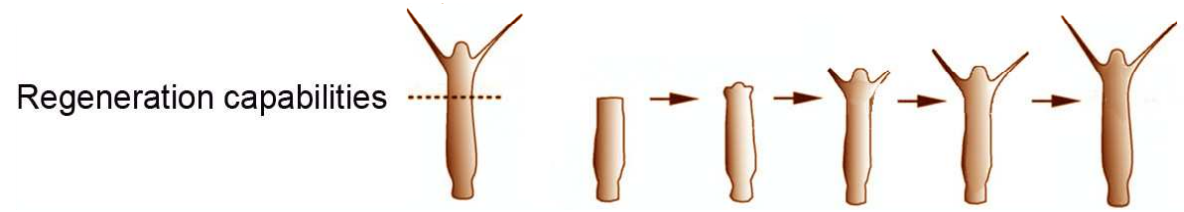

Fig. 11. Different developmental potentials available in the adult polyp.

The toxic effects of organic and inorganic pollutants, i.e, CdTe QDs, can be measured using Hydra, due to its unique developmental potentials. The toxicant under investigation can be added to the medium bathing living polyps and the effects on morphology, reproductive and regeneration capabilities can be quantified by standardised protocols. Upper panel: alteration of morphological traits can be measured by assigning numerical scores to progressive morphological changes (Wilby, 1988)(see below). Middle panel: upon regular feeding, the animals undergo asexual reproduction through budding: the number of buds produced by a single polyp over two weeks can be expressed as reproductive rate, which is altered in presence of toxicants. Lower panel: initially reported by A.Trembley (Trembley, 1744), Hydra polyps can regenerate any missing part after bisection of the body column performed at any level, and the presence of toxicants can irreversibly affect this capability.

CdTe nanocrystals are the most successful example of the colloidal quantum dots directly synthesized in aqueous solution. In Figure 12 a schematic representation of the synthesis of TGA-capped QDs is shown. The methodology was first described by Gao (Gao M, 1998) and it is routinely employed in many laboratories, although modifications have been further developed to increase photoluminescence, quantum yields, or for specific applications in 
various fields ranging from light harvesting and energy transfer to biotechnology (Gaponik and Rogach, 2010). The water-soluble CdTe QDs we analysed using Hydra were surfacecapped with thioglycolic acid (TGA) or stabilized by glutathione (GSH), synthesized as described (Rogach and Lesnyak, 2007) and present a mean diameter of 3.1nm and 3.6nm, respectively .

In our previous studies using CdSe/ZnS QDs or CdSe/CdS QRs evident toxicity signs were not detected, even at the highest QD dose tested (300nM) (Tortiglione et al., 2007). In those cases, nanocrystal synthesis was accomplished by burying a CdSe inner core into a ZnS or CdS shell, then wrapping the metal core/shell by an amphiphilic polymer, further stabilised by conjugation to PEG molecules. The CdTe QDs are sized only a few nanometres and differ not only in chemical composition, but also in the synthetic route (directly in aqueous solution) employing different compounds (thioglycolic acid or glutathione...) as stabilising molecules. These differences drove our comparative toxicity studies using CdTe QDs and testing different concentrations and exposure times (Tino et al., 2011).

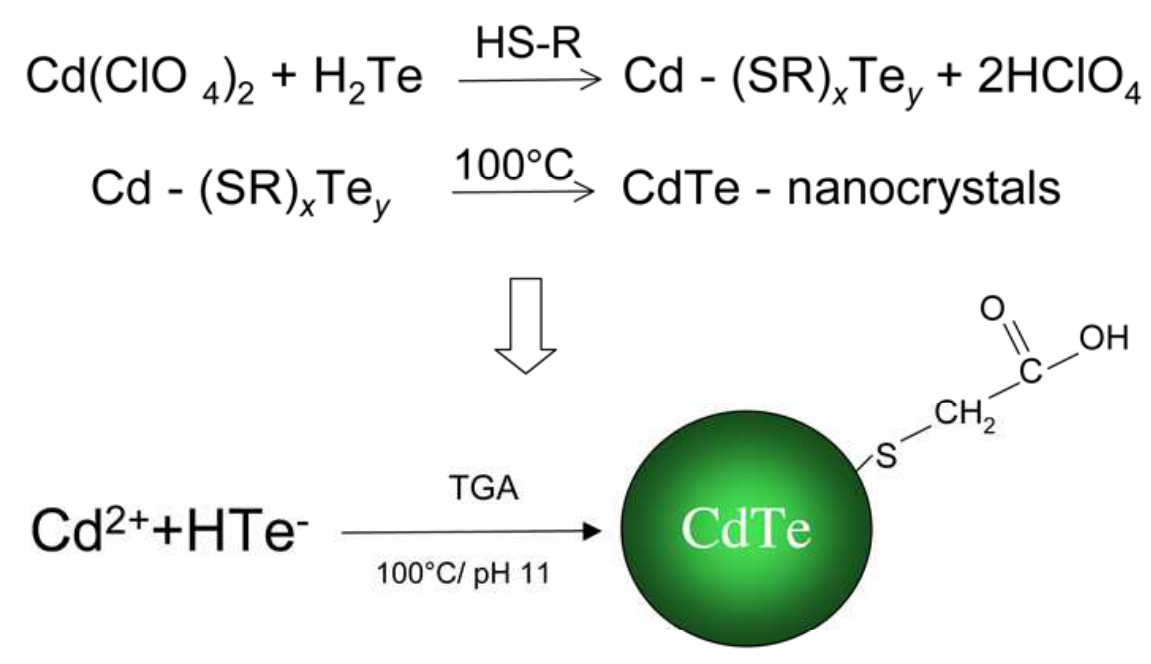

Fig. 12. Schematic representation of TGA capped QDs

The basics of the aqueous synthesis of thiol-capped CdTe NCs. In a typical standard synthesis, $\mathrm{Cd}\left(\mathrm{ClO}_{4}\right)$ salts are dissolved in water, and an appropriate amount of the thiol stabilizer is added under stirring, followed by adjusting the $\mathrm{pH}$ by dropwise addition of $\mathrm{NaOH}$. Under stirring, $\mathrm{H}_{2}$ Te gas is then passed through the solution together with a slow nitrogen flow. CdTe NC precursors are formed at this stage; formation and growth of NCs proceed upon refluxing at $100^{\circ} \mathrm{C}$ under open-air conditions with a condenser attached (from (Rogach and Lesnyak, 2007).

When challenging living polyps to CdTe QDs, adverse effects on animal behaviour and morphology were immediately observed. In Figure 13 the pictures of polyps carrying progressive damages are shown. These different damages have been annotated using a 
scoring system ranging from 10 (healthy polyps) to zero (disintegrated animals) (Wilby, 1990), and already used for toxicological studies in Hydra. This system can be efficiently adopted to compare toxicity of diverse compounds or the sensitivity of different species to a given substance.

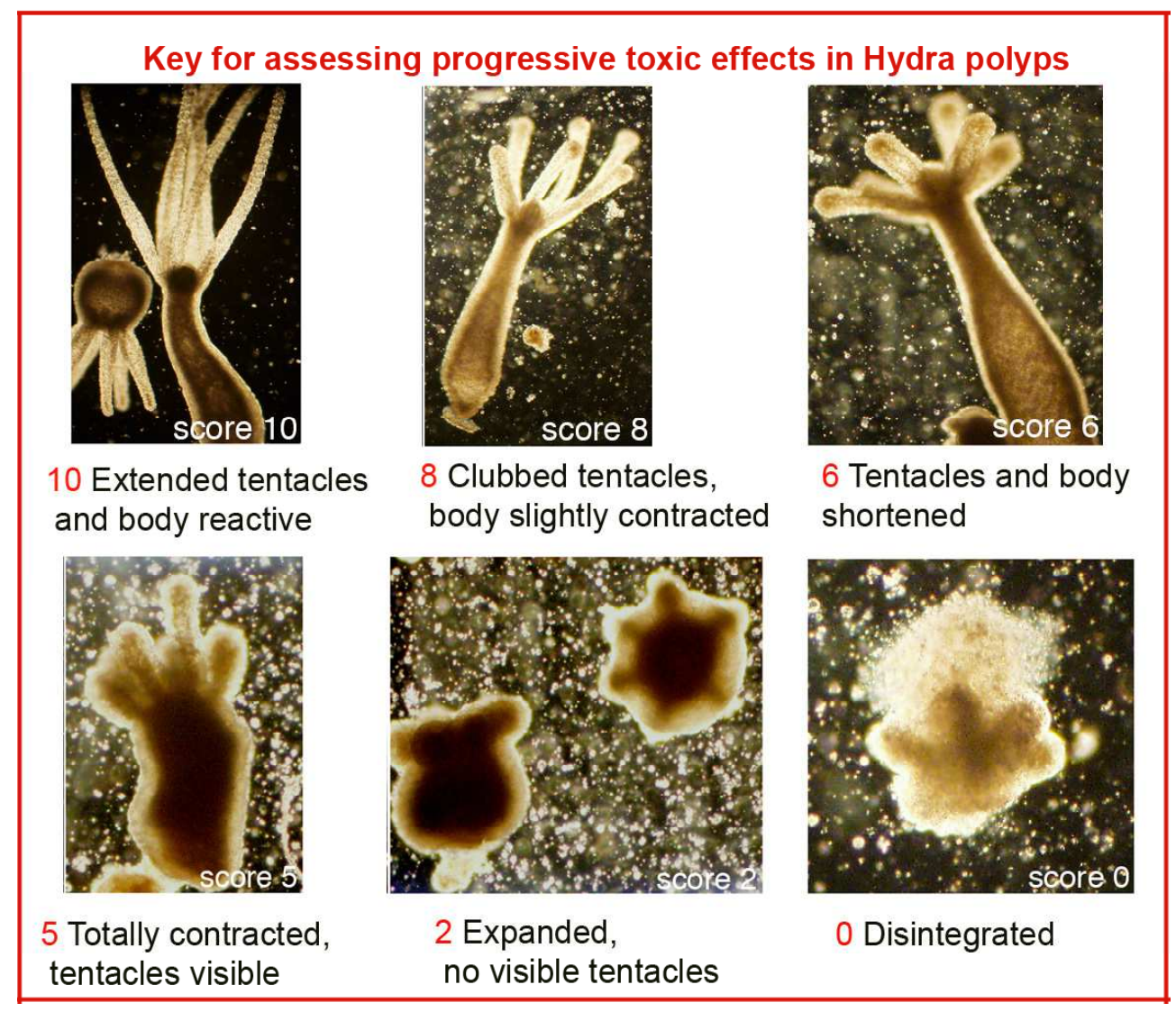

Fig. 13. Score system to assess toxic effects on Hydra

Examples of morphological alterations induced by treatment of living Hydra with CdTe QDs. Animals were incubated with TGA-QDs and observed by a stereomicroscope over a period of $72 \mathrm{~h}$. Images show progressive morphological changes scored from 10 down to 0 , according to the scoring system previously developed (Wilby, 1988)

By fluorescence microscopy we observed intense staining in animals treated with the highest tested QD concentration (300nM), indicating QD uptake (Figure 14). At lower concentrations, the low fluorescent staining did not allow imaging.

Elemental analysis by Inductively Coupled Plasma Atomic Emission Spectrometer (ICPAES) confirmed the internalization of the CdTeQDs (Ambrosone et al, unpublished). 


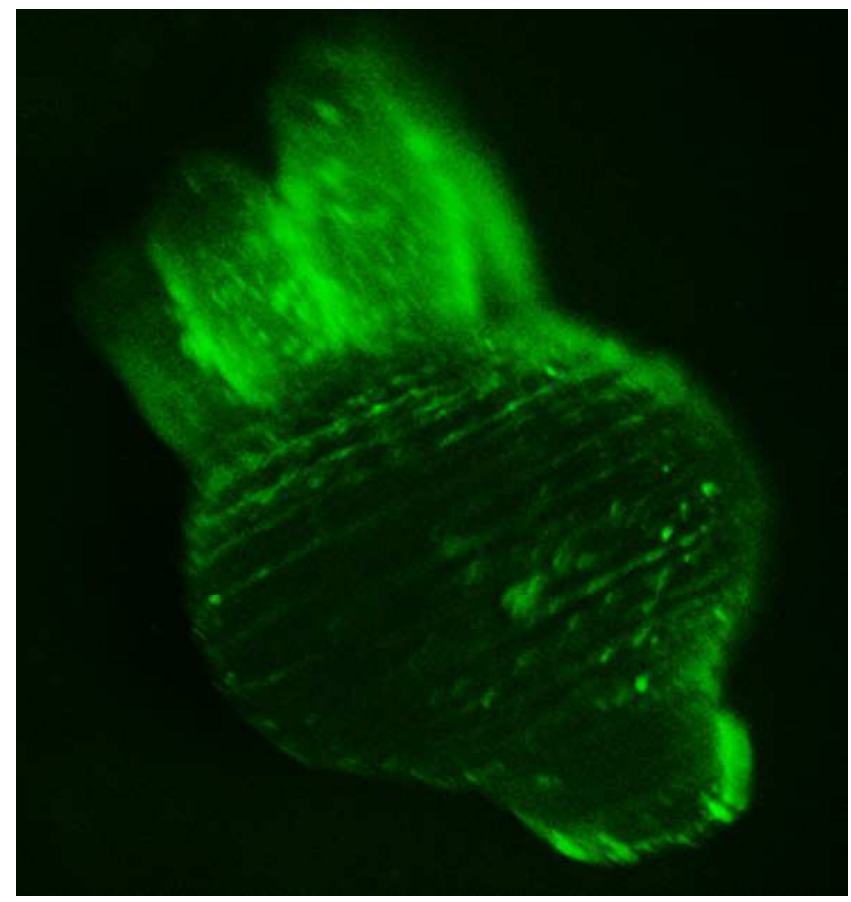

Fig. 14. In vivo fluorescence image of Hydra treated with 300nM TGA-QDs

Polyps were challenged with CdTe QDs and imaged after 2 hours of incubation. The polyp appears contracted, the tentacles clubbed, shortened. The fluorescence is uniform all along the animal (body and tentacles), drawing straight lines perpendicular to the main oralaboral axis, and corresponding to membranes belonging to adjacent cells aligned during contraction. Granular structures are also present, indicating the initial uptake of QDs by ectodermal cells.

We performed acute toxicity tests (by exposing the animals for two hours to QDs and then monitoring the morphological scores), and chronic toxicity tests performing continuous incubation with the QDs (Ambrosone et al, unpublished). Under both acute and chronic treatment the median score values decreased with progressive exposure time, indicating toxic effect (see Figure 15A). After $72 \mathrm{hr}$ of continuous incubation with 25nM QDs, all animals showed score value equal to zero, meaning that were all fully disintegrated. In Figure 15B, the distribution of the different scores among the treated animals is shown at each time point. Untreated animals showed always score 10 (blue bar, highlighted by the upper red arrow), while treatment with QDs causes a decrease in the score values, more pronounced for the higher QD concentration tested $(25 \mathrm{nM})$. In this latter case after $72 \mathrm{hr}$ of continuous incubation all animals were fully disintegrated, as highlighted by the red arrows of Figure 15B.

The toxicity of CdTe QD to Hydra was further evaluated using a different method, based on mortality. The number of death animals was used for survival statistical analysis, and the Karber-Spearmann (Hamilton, 1977) method used to determinate the median lethal concentration and the median lethal scores, as shown in Figure 15C. 
A

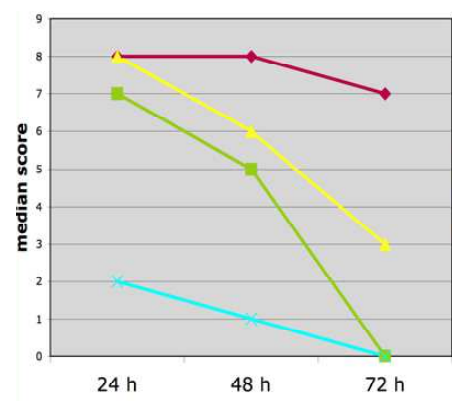

C

\begin{tabular}{|l|l|}
\hline Time & LC50 $(\mathrm{nM})$ \\
\hline $24 \mathrm{~h}$ & 35.6 \\
\hline $48 \mathrm{~h}$ & 28.7 \\
\hline $72 \mathrm{~h}$ & 15.54 \\
\hline \hline Conc. & LT50 (hr) \\
\hline $10 \mathrm{nM}$ & 89.7 \\
\hline $25 \mathrm{nM}$ & 50.4 \\
\hline
\end{tabular}

B
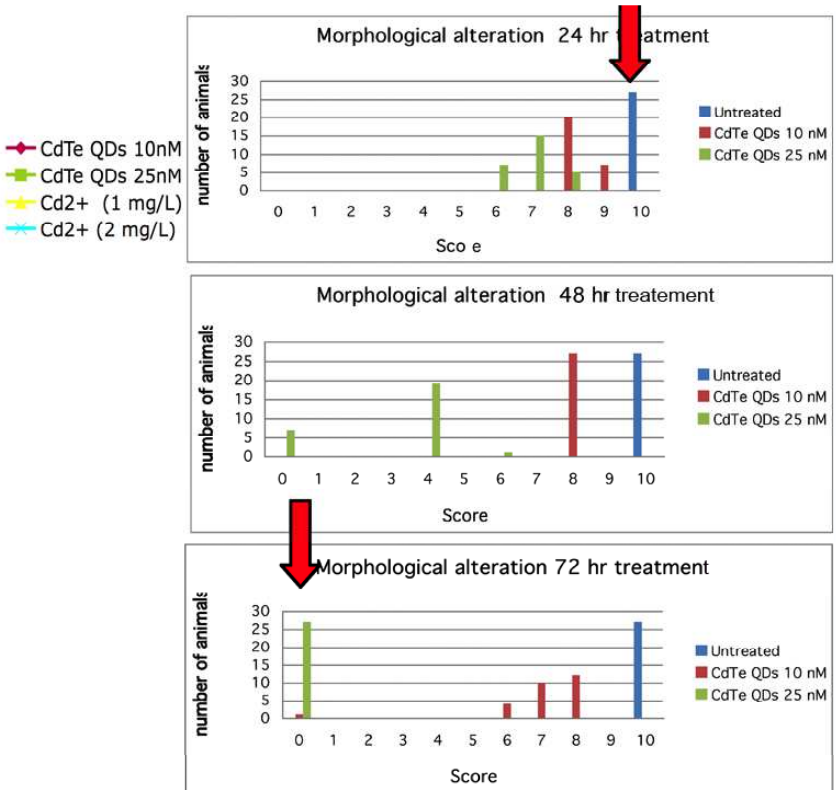

Fig. 15. Methods used to evaluate the toxicity of CdTe-QDs on Hydra

Two different methods can be used to assess the toxicity of a given compound on Hydra. The first method (used in A and B) is based on the evaluation of animal morphological traits, while the second one $(C)$ is based on survival rates. In A the time response toxicity curves to equivalent TGA-QD concentrations are compared to the curves obtained by two different concentrations of $\mathrm{Cd}$ salts. $25 \mathrm{Hydra}$ were treated with the indicated compound and morphological scores were monitored over 24,48 and $72 \mathrm{hr}$. In B the number of the animals presenting different scores are reported for each time point in the three graphs $(24,48,72 \mathrm{hr})$. The red arrows highlights that the score values decreasing from ten (untreated animals) to zero obtained with $25 \mathrm{nM}$ concentration, after $72 \mathrm{hr}$ of incubation. In $\mathrm{C}$ the median lethal time and median lethal concentration were calculated using the Sperman-Karber method.

In this way sub-lethal doses were determined and used for assessing the potential longterm toxic effects induced by CdTe QDs on Hydra reproductive capabilities (Ambrosone et al., 2011; Tino et al., 2011). Growth rate of Hydra tissue is regulated by the epithelial cell cycle, which normal length (about 3 days) is controlled by environmental conditions, i.e., the feeding regime (Bosch and David, 1984). Thus, for a given feeding condition, the growth rate is an indirect measure of the Hydra tissue growth and cell viability. The number of individuals generated by an adult polyps over two-three weeks can be used to calculate the growth rates constant $(\mathrm{k})$, which is the slope of the regression line using the standard equation of logarithmic growth: $\ln \left(n / n^{\circ}\right)=k t$ (where $n$ is the number of individuals at the time $t$, and $n^{\circ}$ is the number of the founder polyps). Representative growth rate curves determined for QD treated and untreated animals are shown in the graph of Figure 15, and indicate $\mathrm{k}$ values lower for QD treated animals compared to control. These differences were found significant by statistical analysis of repeated experiments (Ambrosone et al, unpublished). 
Regeneration efficiencies were also estimated bisecting the animals and allowing regeneration in presence of QDs. During the first $48-72 \mathrm{hr}$ post amputation a great percentage of animals treated with the highest QD concentration were unable to regenerate a head and were found as stumps without tentacles (stage 0 ).

Moreover, about $30 \%$ of the bisected animals died, demonstrating the high QD toxicity (see Figure 16, upper panel).
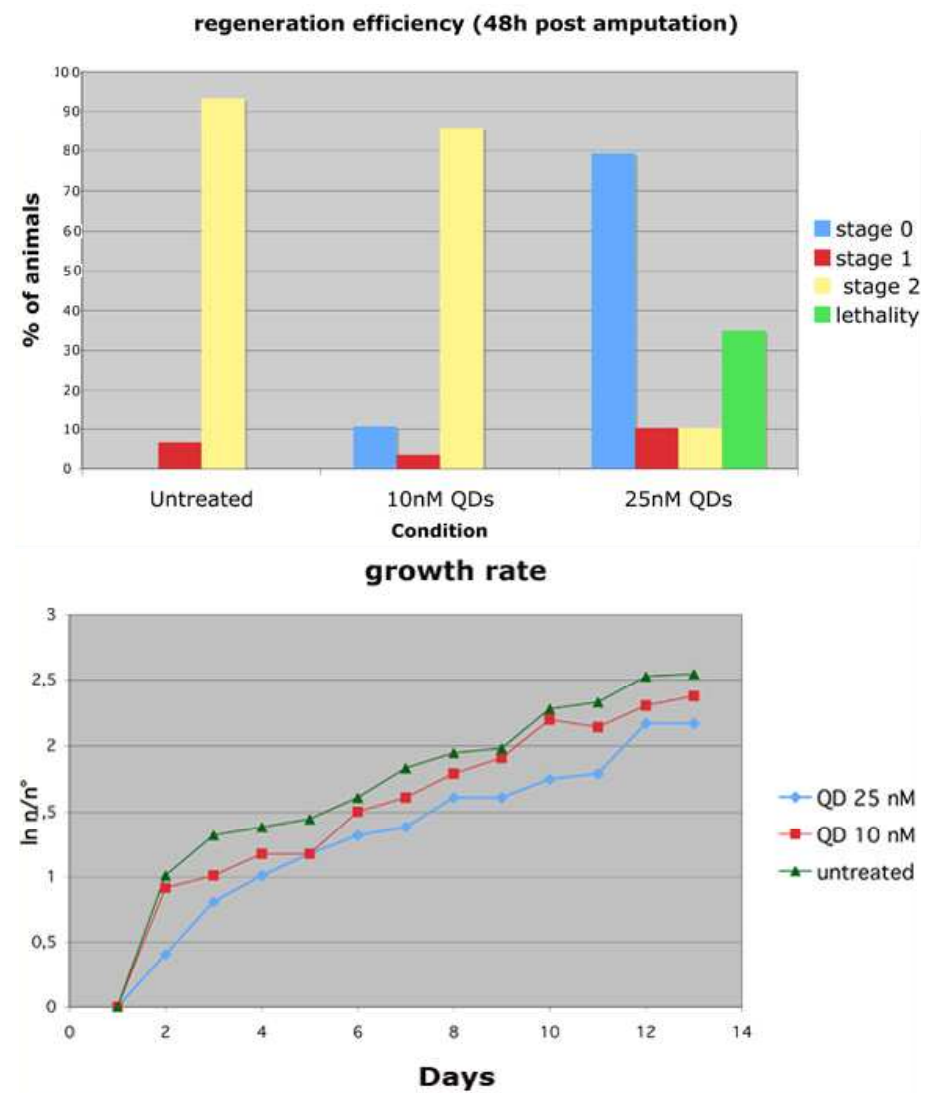

Fig. 16. Impact of CdTe QDs on regeneration efficiency and growth rates

Upper panel: representative histogram showing the impact of QDs on Hydra head regeneration. The regeneration stages are classified as in Fig.2. Basically, stage zero indicate the complete inhibition of regeneration (zero tentacles); stage 1, indicates heads with aberrant tentacles (one or two), while stage 2 indicates normal regeneration (tentacles from four to six at this time). The lowest QD concentration tested, $10 \mathrm{nM}$, does not impair head regeneration, while the $25 \mathrm{nM}$ dose inhibits the whole process, and furthermore, causes lethality. Lower panel: influence of the QD treatment on Hydra population growth rate. Population growth test started with a population of four full-grown Hydra, incubated 24h with the indicated dose of QD, washed out and monitored every day for bud detachment. The logarithmic growth rate constant $(\mathrm{k})$ is the slope of the regression line using the 
standard equation of logarithmic growth: $\ln (\mathrm{n} / \mathrm{n} 0)=\mathrm{kt}$. In this representative graph the regression line is not drawn. Polyps treated with the highest QD concentration were impaired in the reproductive capabilities, as shown by the altered ratio $n / n^{\circ}$ along the monitored period (Ambrosone et al, unpublished).

We also compared the effects of thioglycolic acid capped QDs (TGA-QDs) and glutathione capped QDs (GSH-QDs), by using the same approaches and observed that although both nanocrystals were toxic, the most severe effects were induced by TGA capped QDs (Tino et al., 2011). This confirms the importance of the nanocrystal surface chemistry in the interaction with living cells.

The availability of a Hydra whole genome sequence allowed us to study the nanoparticleinduced cellular changes at three levels: non-genomic, genomic and epigenetic. The genes selectively involved in the apoptosis or in the necrosis process, as diverse as the Hymyc transcription factor, Caspase 3, Superoxide dismutase, Hsp70 have been analysed by quantitative real time PCR, and compared to the expression of animals treated with free cadmium salts (Ambrosone et al, unpublished). Aside from genotoxic effects, as nanoparticles could cause more subtle changes to living cells, such as long-term effects on gene expression, after the QD signal has been removed, epigenetic effects are being addressed. At the current stage of investigation, the elucidation of the possible molecular pathways activated by CdTe QDs appears rather complex, and it may concern universal stress response genes, $\mathrm{Cd}$ specific response genes or novel unidentified signalling cascades, initiated by the QDs at the cell surface.

In conclusion, by using different approaches, from in vivo evaluation of morphological traits to the impact on growth rate and regeneration, to the molecular analysis of the genes potentially involved in the QD response, we determined animal behaviours and toxicological effects played by CdTe QDs, and proposed Hydra as a valuable model for nanotoxicology studies.

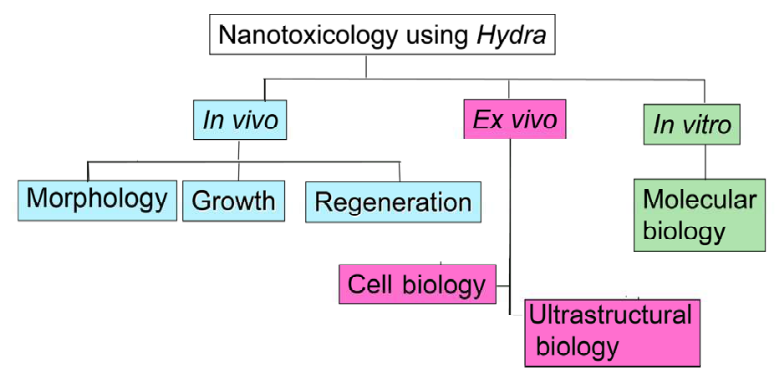

Fig. 17. Methodological approaches for nanotoxicology using Hydra as model system

The impact of nanoparticles on a living organism can be assessed by using the freshwater polyp Hydra. This system allows to evaluate in vivo, ex vivo and in vitro the responses of a whole animal to short or long exposures of any organic and inorganic compound, unless unstable in Hydra culture medium.

\section{Hydra as a widely applicable tool for high-throughput screens of nanoparticles biocompatibility and (eco)toxicity}

The use of simple model organisms to dissect complex biological processes has permitted biology to advance at an impressive pace, and the knowledge generated by integrating 
genetic and biochemical studies has allowed scientists to begin to understand the molecular basis of complex diseases such as cancer and diabetes. Several pharmaceutical companies developed research programs that use simple organisms to identify and validate drug targets. Since the production of newer engineered nanomaterials and their applications has exponentially increased, high-throughput screens (HTS) are required to evaluate their impact on human and environmental health. In the above sections I gave some examples demonstrating the use of Hydra as valuable model system for the dissection of biological processes evoked by metal based nanocrystals. Because of the small size, short generation time, high fecundity and cost effective maintenance, it can also be used for HTS of nanoparticle biocompatibility, environmental and animal impact. Standard microtiter plates can be used for whole animal assays to assess toxicity and identify the underlying mechanisms by simply changing multiple experimental conditions in adjacent wells, such as medium composition, $\mathrm{pH}$, presence of specific inhibitors/competitors/agonists, and the trials can all be run in parallel, in large scale enabling statistical treatment of the data.

In addition, the new genomic resources open the way to the molecular toxicology field. Several gene families that defend against chemical stressors have been identified in other cnidarians and include oxidases, various conjugating enzymes, ATP-dependent efflux transporters, oxidative detoxification proteins, as well as various transcription factors (Goldstone, 2008; Goldstone et al., 2006). The modulation of their expression in Hydra exposed to the new class of stressors, i.e. nanomaterials, may easily help to dissect the mechanisms underlying nanoparticle toxicity, and to identify those shared by other stressors and those unique to the nanomaterial under investigation.

Considering the key role played by cnidarians in freshwater, estuarine and reefs environments, the obtained results would be of invaluable importance for ecotoxicological studies as well. As nanoparticles may enter natural waters through sewage effluent and landfill leakages and present unknown risk to aquatic species, invertebrate testing may be used not only to advance the level of knowledge in nanoecotoxicology, but also for investigating behaviour and bioavailability of engineered nanoparticles in the aquatic environments.

\section{Conclusion}

Since the first publication on Hydra challenged with functional QDs (Tortiglione et al., 2007), the scientific community caught the advantages offered by this simple model to address nanotechnological issues, and many groups involved in the synthesis of nanomaterials demanded to test their synthetic products on Hydra. A picture of living polyps exposed to different nanoparticles is shown in Figure 18. We are currently investigating for each material the cell and molecular bases of interaction with Hydra, from the internalization route relying on the chemistry surface properties, to the molecular machinery activated by these nanosized objects. These results would be of valuable help when designing nanodevices to be interfaced with eukaryotic living cells. Once established the rules governing such interactions we will move toward the functionalization of the nanoparticles, combing the new size dependent physical properties to the specificity of the bioactive conjugated moiety to achieve targeted functioning.

Despite the initial studies limited to fluorescent semiconductor nanocrystals (QDs and QRs) for imaging purposes, the wide arrays of physical properties offered by nanoparticles of different materials supplies a corresponding wide repertoire of new tools to probe biological 
phenomena. Superparamagnetic nanoparticles $\left(\mathrm{Fe}_{\mathrm{x}} \mathrm{O}_{\mathrm{y}}\right)$ could be employed for local heat generation (magnetic hyperthermia) under an alternating magnetic field, and thus exploited for selective cell destruction. Up to date, magnetic hyperthermia has been studied for cancer treatment but not applied to basic research, i.e. to obtain loss of function by cell ablation. Similarly, the property of some nanomaterials to strongly absorb NIR irradiation for conversion into thermal energy has been tested for phototherapy in cellular models, but not as universal tool for cell/animal biology. Nowadays nanotechnology allow to revisit traditional methodologies and extract yet unobserved or inaccessible information in vitro or in vivo. Only the cross-talk between different disciplines (biologists /chemists/physics) can bridge separate expertises, develop innovative tools and successfully apply them to modern research.
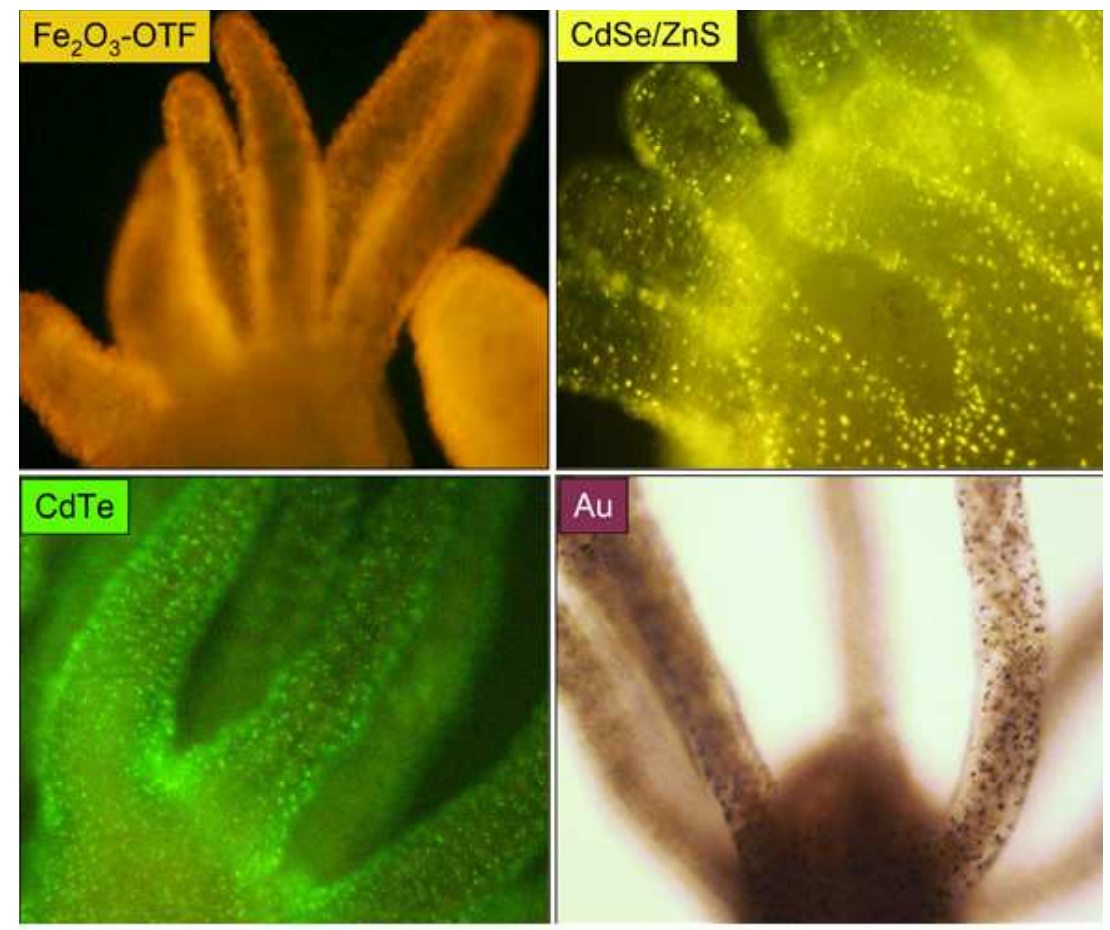

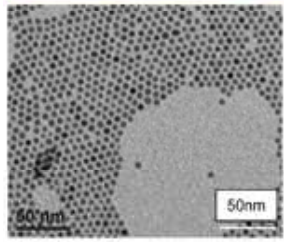

$\mathrm{Fe}_{2} \mathrm{O}_{3}$

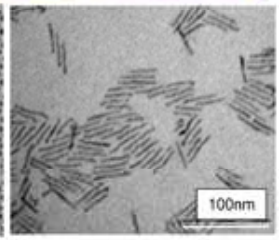

$\mathrm{CdSe} / \mathrm{ZnS}$

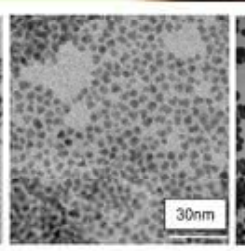

$\mathrm{CdTe}$

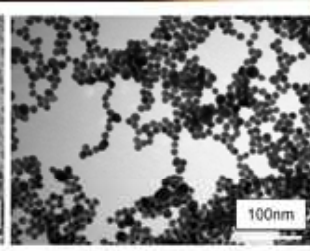

$\mathrm{Au}$

Fig. 18. Labelling Hydra with nanocrystals

In vivo imaging of polyps incubated with different nanocrystals, whose interaction with Hydra in terms of biocompatibility and toxicology is currently in progress. Upper left panel: picture of a living Hydra incubated with bifunctional conjugates $\left(\mathrm{Fe}_{2} \mathrm{O}_{3}-\mathrm{OTF}\right)$ based on the 
linkage of inorganic $\mathrm{Fe}_{2} \mathrm{O}_{3}$ nanoparticles to organic oligothiophene fluorophores (OTFs). Nanoparticle core diameter: $8 \mathrm{~nm}$; emission $\lambda \max =605 \mathrm{~nm}$ (Quarta et al., 2008). The presence of the fluorophore allows to track nanoparticle cell uptake, while the magnetic properties can be exploited for magnetic separation of the labelled cells. Upper right panel: Hydra labelled with fluorescent rod shaped nanocrystals, PEG coated CdSe/ZnS QRs. Nanoparticle diameter: 3,5nm, lenght 34nm; emission $\lambda \max =592 \mathrm{~nm}$. These two type of nanocrystals were a precious gift from Dr. Teresa Pellegrino (Italian Institute of Technology, Genova, Italy). Lower left panel: CdTe QD amino stabilised, by cysteamine, (emission $\lambda \max =510 \mathrm{~nm}$, diameter: $2.6 \mathrm{~nm}$ ) were added to the medium bathing living Hydras and imaged after $4 \mathrm{hr}$. These nanocrystals were a generous gift from Dr. Andrey Rogach, City University of Hong Kong, Hong Kong, SAR. Lower right panel: Hydra treated with PEG coated gold nanoparticles (diameter: $14 \mathrm{~nm}$ ) These nanocrystals were surface modified to introduce positive charges on the surface (de la Fuente et al, unpublished) and are internalized at high rate by Hydra ectodermal cells. These nanocrystals were supplied by Dr. Jesus de la Fuente, University of Zaragoza, Spain. At the bottom representative TEM images of the samples above described were generously supplied by the corresponding providers.

\section{Acknowledgment}

I sincerely thank all the co-authors of the papers on Hydra/nanoparticles that I mentioned in this chapter, and those that are in preparation. As I stated earlier, these interdisciplinary works were made possible by the tight collaboration between different groups and expertises, and a great effort stands beyond each one. In particular, I thank Dr. Teresa Pellegrino (Italian Institute of Technology, Genova, Italy), as with her precious collaboration in material synthesis the whole research line was launched; dr.Angela Tino, (Institute of Cybernetics, National research Council of Italy) for daily discussions and data analysis; and people from my lab which shared challenges and enthusiasm for this work.

This work is supported by the NanoSci-ERA net project NANOTRUCK (2009-2012).

\section{References}

Alivisatos, A.P., Gu, W. and Larabell, C. (2005) Quantum dots as cellular probes. Annu Rev Biomed Eng, 7, 55-76.

Ambrosone, A., Marchesano, V., Mattera, L., Tino, A., Tortiglione, C. (2011) Bridging the fields of nanoscience and toxicology: nanoparticle impact on biological models. In Parak, W.J., Yamamoto, K., Osinski, M. (ed.), Colloidal Quantum Dots/Nanocrystals for Biomedical Applications VI. SPIE, Bellingham, WA, Washington, USA, Vol. 7909.

Auffan, M., Rose, J., Bottero, J.Y., Lowry, G.V., Jolivet, J.P. and Wiesner, M.R. (2009) Towards a definition of inorganic nanoparticles from an environmental, health and safety perspective. Nat Nanotechnol, 4, 634-641.

Baun, A., Hartmann, N.B., Grieger, K. and Kusk, K.O. (2008) Ecotoxicity of engineered nanoparticles to aquatic invertebrates: a brief review and recommendations for future toxicity testing. Ecotoxicology, 17, 387-395.

Bellis, S.L., Laux, D.C. and Rhoads, D.E. (1994) Affinity purification of Hydra glutathione binding proteins. FEBS Lett, 354, 320-324.

Bode, H.R. (2003) Head regeneration in Hydra. Dev Dyn, 226, 225-236. 
Bosch, T.C. and David, C.N. (1984) Growth regulation in Hydra: relationship between epithelial cell cycle length and growth rate. Dev Biol, 104, 161-171.

Bruchez, M., Moronne, M., Gin, P., Weiss, S. and Alivisatos, A.P. (1998) Semiconductor nanocrystals as fluorescent biological labels. Science, 281, 2013-2016.

Carbone, L., Nobile, C., De Giorgi, M., Sala, F.D., Morello, G., Pompa, P., Hytch, M., Snoeck, E., Fiore, A., Franchini, I.R., Nadasan, M., Silvestre, A.F., Chiodo, L., Kudera, S., Cingolani, R., Krahne, R. and Manna, L. (2007) Synthesis and micrometer-scale assembly of colloidal CdSe/CdS nanorods prepared by a seeded growth approach. Nano Lett, 7, 2942-2950.

Cattaneo, A.G.G., R; Chiriva-Internati, M; Bernardini, G (2009) Ecotoxicology of nanomaterials: the role of invertebrate testing. ISJ - Invertebrate Survival Journal, 6, 78-97.

Chapman, J.A., Kirkness, E.F., Simakov, O., Hampson, S.E., Mitros, T., Weinmaier, T., Rattei, T., Balasubramanian, P.G., Borman, J., Busam, D., Disbennett, K., Pfannkoch, C., Sumin, N., Sutton, G.G., Viswanathan, L.D., Walenz, B., Goodstein, D.M., Hellsten, U., Kawashima, T., Prochnik, S.E., Putnam, N.H., Shu, S., Blumberg, B., Dana, C.E., Gee, L., Kibler, D.F., Law, L., Lindgens, D., Martinez, D.E., Peng, J., Wigge, P.A., Bertulat, B., Guder, C., Nakamura, Y., Ozbek, S., Watanabe, H., Khalturin, K., Hemmrich, G., Franke, A., Augustin, R., Fraune, S., Hayakawa, E., Hayakawa, S., Hirose, M., Hwang, J.S., Ikeo, K., Nishimiya-Fujisawa, C., Ogura, A., Takahashi, T., Steinmetz, P.R., Zhang, X., Aufschnaiter, R., Eder, M.K., Gorny, A.K., Salvenmoser, W., Heimberg, A.M., Wheeler, B.M., Peterson, K.J., Bottger, A., Tischler, P., Wolf, A., Gojobori, T., Remington, K.A., Strausberg, R.L., Venter, J.C., Technau, U., Hobmayer, B., Bosch, T.C., Holstein, T.W., Fujisawa, T., Bode, H.R., David, C.N., Rokhsar, D.S. and Steele, R.E. (2010) The dynamic genome of Hydra. Nature, 464, 592-596.

Choi, A.O., Brown, S.E., Szyf, M. and Maysinger, D. (2008) Quantum dot-induced epigenetic and genotoxic changes in human breast cancer cells. J Mol Med, 86, 291-302.

Demir E, V.G., Kaya B, Creus A, Marcos R. (2010) Genotoxic analysis of silver nanoparticles in Drosophila. Nanotoxicology, in press, 1-8.

Derfus, A.C., WCW; Bhatia, SN. (2004) Probing the Cytotoxicity of Semiconductor Quantum Dots. Nano Letters, 4, 11-18.

Fischer, H.C. and Chan, W.C. (2007) Nanotoxicity: the growing need for in vivo study. Curr Opin Biotechnol, 18, 565-571.

Galliot, B., Chera, S. (2010) The Hydra model: disclosing an apoptosis-driven generator of Wnt-based regeneration. Trends Cell Biol, 20, 514-523.

Galliot, B. and Ghila, L. (2010) Cell plasticity in homeostasis and regeneration. Mol Reprod Dev, 77, 837-855.

Galliot, B., Miljkovic-Licina, M., de Rosa, R. and Chera, S. (2006) Hydra, a niche for cell and developmental plasticity. Semin Cell Dev Biol, 17, 492-502.

Gao M, K.S., Mvhwald H, Rogach AL, Kornovski A, Eyhmiller A, Weller Horst. (1998) Strongly photoluminescent CdTe nanocrystals by proper surface modification. J Phys Chem Biol, 102, 8360-8363.

Gaponik, N. and Rogach, A.L. (2010) Thiol-capped CdTe nanocrystals: progress and perspectives of the related research fields. Phys Chem Chem Phys, 12, 8685-8693. 
Goldstone, J.V. (2008) Environmental sensing and response genes in cnidaria: the chemical defensome in the sea anemone Nematostella vectensis. Cell Biol Toxicol, 24, 483-502.

Goldstone, J.V., Hamdoun, A., Cole, B.J., Howard-Ashby, M., Nebert, D.W., Scally, M., Dean, M., Epel, D., Hahn, M.E. and Stegeman, J.J. (2006) The chemical defensome: environmental sensing and response genes in the Strongylocentrotus purpuratus genome. Dev Biol, 300, 366-384.

Grosvenor, W., Bellis, S.L., Kass-Simon, G. and Rhoads, D.E. (1992) Chemoreception in hydra: specific binding of glutathione to a membrane fraction. Biochim Biophys Acta, $1117,120-125$.

Hamilton, M.A., Russo, R.C., Thurston, R.V. (1977) Trimmed Spearman-Karber Method for Estimating Median Lethal Concentrations in Toxicity Bioassays. Environmental Science \& Technology, 11, 714-719.

Holdway, D.A., Lok, K. and Semaan, M. (2001) The acute and chronic toxicity of cadmium and zinc to two hydra species. Environ Toxicol, 16, 557-565.

Holstein, T.W., Hobmayer, E. and Technau, U. (2003) Cnidarians: an evolutionarily conserved model system for regeneration? Dev Dyn, 226, 257-267.

Hoshino, A., Fujioka, K., Oku, T., Suga, M., Sasaki, Y.F., Ohta, T., and Yasuhara, M., Suzuki, K., and Yamamoto, K. . (2004) Physicochemical properties and cellular toxicity of nanocrystal quantum dots depend on their surface modification. Nano Lett., 4, 21632169.

Hu, J., Li, L., Yang, W., Manna, L., Wang, L. and Alivisatos, A.P. (2001) Linearly polarized emission from colloidal semiconductor quantum rods. Science, 292, 2060-2063.

Huynh, W.U., Dittmer, J.J. and Alivisatos, A.P. (2002) Hybrid nanorod-polymer solar cells. Science, 295, 2425-2427.

Jiang, W., Kim, B.Y., Rutka, J.T. and Chan, W.C. (2008) Nanoparticle-mediated cellular response is size-dependent. Nat Nanotechnol, 3, 145-150.

Karntanut, W. and Pascoe, D. (2000) A comparison of methods for measuring acute toxicity to Hydra vulgaris. Chemosphere, 41, 1543-1548.

Karntanut, W. and Pascoe, D. (2002) The toxicity of copper, cadmium and zinc to four different Hydra (Cnidaria: Hydrozoa). Chemosphere, 47, 1059-1064.

Karntanut, W. and Pascoe, D. (2005) Effects of removing symbiotic green algae on the response of Hydra viridissima (Pallas 1776) to metals. Ecotoxicol Environ Saf, 60, 301-305.

Kirchner, C., Liedl, T., Kudera, S., Pellegrino, T., Munoz Javier, A., Gaub, H.E., Stolzle, S., Fertig, N. and Parak, W.J. (2005) Cytotoxicity of colloidal CdSe and CdSe/ZnS nanoparticles. Nano Lett, 5, 331-338.

Lee, J.J., K.; Kim, J.; Park, K.; Lim, K.H.; Yoon, T.H.; Choi, K. (2009) Acute Toxicity of Two CdSe/ZnSe Quantum Dots with Different Surface Coating in Daphnia magna Under Various Light Conditions. Environmental Toxicology, 25.

Lenhoff, H.M., Muscatine, L. and Davis, L.V. (1968) Coelenterate biology: experimental research. Science, 160, 1141-1146.

Lewinski, N., Colvin, V. and Drezek, R. (2008) Cytotoxicity of nanoparticles. Small, 4, 26-49.

Loomis, W.F. (1955) Glutathione control of the specific feeding reactions of Hydra. Ann. N. Y. Acad. Sci, 62, 208-209.

Loomis, W.F., and Lenhoff, H. M. (1956) Growth and sexual differentiation of Hydra in mass culture. . J. Exp. Zool. , 132, 555-574. 
Lovric, J., Bazzi, H.S., Cuie, Y., Fortin, G.R., Winnik, F.M. and Maysinger, D. (2005a) Differences in subcellular distribution and toxicity of green and red emitting CdTe quantum dots. J Mol Med, 83, 377-385.

Lovric, J., Cho, S.J., Winnik, F.M. and Maysinger, D. (2005b) Unmodified cadmium telluride quantum dots induce reactive oxygen species formation leading to multiple organelle damage and cell death. Chem Biol, 12, 1227-1234.

Malvindi, M.A., Carbone, L., Quarta, A., Tino, A., Manna, L., Pellegrino, T. and Tortiglione, C. (2008) Rod-shaped nanocrystals elicit neuronal activity in vivo. Small, 4, 17471755 .

Maynard, A.D., Aitken, R.J., Butz, T., Colvin, V., Donaldson, K., Oberdorster, G., Philbert, M.A., Ryan, J., Seaton, A., Stone, V., Tinkle, S.S., Tran, L., Walker, N.J. and Warheit, D.B. (2006) Safe handling of nanotechnology. Nature, 444, 267-269.

Medintz, I.L., Uyeda, H.T., Goldman, E.R. and Mattoussi, H. (2005) Quantum dot bioconjugates for imaging, labelling and sensing. Nat Mater, 4, 435-446.

Michalet, X., Pinaud, F.F., Bentolila, L.A., Tsay, J.M., Doose, S., Li, J.J., Sundaresan, G., Wu, A.M., Gambhir, S.S. and Weiss, S. (2005) Quantum dots for live cells, in vivo imaging, and diagnostics. Science, 307, 538-544.

Miller, D.J., Hemmrich, G., Ball, E.E., Hayward, D.C., Khalturin, K., Funayama, N., Agata, K. and Bosch, T.C. (2007) The innate immune repertoire in cnidaria--ancestral complexity and stochastic gene loss. Genome Biol, 8, R59.

Moss, S.E. and Morgan, R.O. (2004) The annexins. Genome Biol, 5, 219.

Pappas, T.C., Wickramanyake, W.M., Jan, E., Motamedi, M., Brodwick, M., Kotov, N.A. (2007) Nanoscale engineering of a cellular interface with semiconductor nanoparticle films for photoelectric stimulation of neurons. Nano Lett, 7, 513-519.

Pascoe, D., Carroll, K., Karntanut, W. and Watts, M.M. (2002) Toxicity of 17alphaethinylestradiol and bisphenol A to the freshwater Cnidarian Hydra vulgaris. Arch Environ Contam Toxicol, 43, 56-63.

Pascoe, D., Karntanut, W. and Muller, C.T. (2003) Do pharmaceuticals affect freshwater invertebrates? A study with the cnidarian Hydra vulgaris. Chemosphere, 51, 521-528.

Pellegrino, T., Manna, L., Kudera, S., Liedl, T., Koktysh, D., Rogach, A., Keller, S., Radler, J., Natile, G., Parak, WJ. (2004) Hydrophobic nanocrystals coated with an amphiphilic polymer shell: A general route to water soluble nanocrystals. Nano Lett. , 4, 703-707.

Pierobon, P., Minei, R., Porcu, P., Sogliano, C., Tino, A., Marino, G., Biggio, G. and Concas, A. (2001) Putative glycine receptors in Hydra: a biochemical and behavioural study. Eur J Neurosci, 14, 1659-1666.

Pierobon, P., Sogliano, C., Minei, R., Tino, A., Porcu, P., Marino, G., Tortiglione, C. and Concas, A. (2004) Putative NMDA receptors in Hydra: a biochemical and functional study. Eur J Neurosci, 20, 2598-2604.

Pollino, C.A. and Holdway, D.A. (1999) Potential of two hydra species as standard toxicity test animals. Ecotoxicol Environ Saf, 43, 309-316.

Putnam, N.H., Srivastava, M., Hellsten, U., Dirks, B., Chapman, J., Salamov, A., Terry, A., Shapiro, H., Lindquist, E., Kapitonov, V.V., Jurka, J., Genikhovich, G., Grigoriev, I.V., Lucas, S.M., Steele, R.E., Finnerty, J.R., Technau, U., Martindale, M.Q. and Rokhsar, D.S. (2007) Sea anemone genome reveals ancestral eumetazoan gene repertoire and genomic organization. Science, 317, 86-94. 
Quarta, A., Di Corato, R., Manna, L., Argentiere, S., Cingolani, R., Barbarella, G. and Pellegrino, T. (2008) Multifunctional nanostructures based on inorganic nanoparticles and oligothiophenes and their exploitation for cellular studies. J Am Chem Soc, 130, 10545-10555.

Rivera Gil, P., Oberdorster, G., Elder, A., Puntes, V. and Parak, W.J. (2010) Correlating physico-chemical with toxicological properties of nanoparticles: the present and the future. ACS Nano, 4, 5527-5531.

Rogach, A.L.F., T.; Klar, T. A.; Feldmann, J.; Gaponik, N.; and Lesnyak, V.S., A.; Eychmuller, A.; Rakovich, Y. P.; Donegan, J. F. (2007) Aqueous Synthesis of Thiol-Capped CdTe Nanocrystals: State-of-the-Art. J Phys Chem C, 111, 14628-14637.

Schlaepfer, D.D., Bode, H.R. and Haigler, H.T. (1992a) Distinct cellular expression pattern of annexins in Hydra vulgaris. J Cell Biol, 118, 911-928.

Schlaepfer, D.D., Fisher, D.A., Brandt, M.E., Bode, H.R., Jones, J.M. and Haigler, H.T. (1992b) Identification of a novel annexin in Hydra vulgaris. Characterization, cDNA cloning, and protein kinase C phosphorylation of annexin XII. J Biol Chem, 267, 9529-9539.

Smith, A.M., Duan, H., Mohs, A.M. and Nie, S. (2008) Bioconjugated quantum dots for in vivo molecular and cellular imaging. Adv Drug Deliv Rev, 60, 1226-1240.

Sperling, R.A., Pellegrino, T., Li, J.K., Chang, W.H. \& Parak, W.J. . (2006) Electrophoretic separation of nanoparticles with a discrete number of functional groups. Adv. Funct. Mater., 16, 943-948.

Steele, R.E., David, C.N. and Technau, U. (2011) A genomic view of 500 million years of cnidarian evolution. Trends Genet, 27, 7-13.

Tino, A., Ambrosone, A., Mattera, L., Marchesano, V., Susha, A., Rogach, A., Tortiglione, C. (2011) A new in vivo model system to assess the toxicity of semiconductor nanocrystals. International Journal of Biomaterials. Volume 2011, Article ID 792854, 8 pages, doi:10.1155/2011/792854

Tortiglione, C., Quarta, A., Malvindi, M.A., Tino, A. and Pellegrino, T. (2009) Fluorescent nanocrystals reveal regulated portals of entry into and between the cells of Hydra. PLoS One, 4, e7698.

Tortiglione, C., Quarta, A., Tino, A., Manna, L., Cingolani, R. and Pellegrino, T. (2007) Synthesis and biological assay of GSH functionalized fluorescent quantum dots for staining Hydra vulgaris. Bioconjug Chem, 18, 829-835.

Trembley, A. (1744) Memoires PourServira l'Histoire d'un Genre de Polypes d'EauDouce, a Bras en Forme deCornes.

Wilby, O., Tesh JM. (1990) The Hydra assay as an early screen for teratogenic potential. Toxicol in vitro, $4,582-583$.

Wilby, O.K. (1988) The Hydra regeneration assay. Proceedings of workshop organised by Association Francaise de Teratologie,, 108-124.

Williams, A.I., I.T. . (1981) Carbodiimide chemistry: recent advances. Chem. Rev, 81, 589-636. 


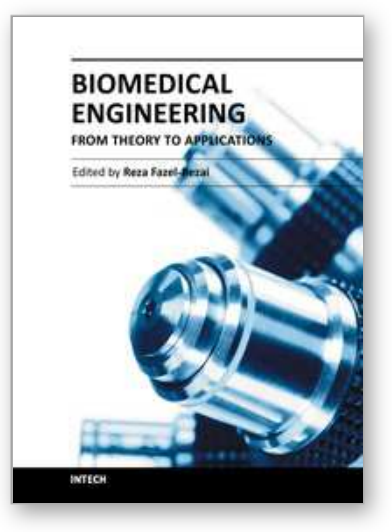

\author{
Biomedical Engineering - From Theory to Applications \\ Edited by Prof. Reza Fazel
}

ISBN 978-953-307-637-9

Hard cover, 486 pages

Publisher InTech

Published online 29, August, 2011

Published in print edition August, 2011

In all different areas in biomedical engineering, the ultimate objectives in research and education are to improve the quality life, reduce the impact of disease on the everyday life of individuals, and provide an appropriate infrastructure to promote and enhance the interaction of biomedical engineering researchers. This book is prepared in two volumes to introduce a recent advances in different areas of biomedical engineering such as biomaterials, cellular engineering, biomedical devices, nanotechnology, and biomechanics. It is hoped that both of the volumes will bring more awareness about the biomedical engineering field and help in completing or establishing new research areas in biomedical engineering.

\title{
How to reference
}

In order to correctly reference this scholarly work, feel free to copy and paste the following:

Claudia Tortiglione (2011). An Ancient Model Organism to Test In Vivo Novel Functional Nanocrystals, Biomedical Engineering - From Theory to Applications, Prof. Reza Fazel (Ed.), ISBN: 978-953-307-637-9, InTech, Available from: http://www.intechopen.com/books/biomedical-engineering-from-theory-toapplications/an-ancient-model-organism-to-test-in-vivo-novel-functional-nanocrystals

\section{INTECH}

open science | open minds

\section{InTech Europe}

University Campus STeP Ri Slavka Krautzeka 83/A 51000 Rijeka, Croatia Phone: +385 (51) 770447

Fax: +385 (51) 686166 www.intechopen.com

\section{InTech China}

Unit 405, Office Block, Hotel Equatorial Shanghai No.65, Yan An Road (West), Shanghai, 200040, China 中国上海市延安西路65号上海国际贵都大饭店办公楼405单元 Phone: +86-21-62489820

Fax: +86-21-62489821 
(C) 2011 The Author(s). Licensee IntechOpen. This chapter is distributed under the terms of the Creative Commons Attribution-NonCommercialShareAlike-3.0 License, which permits use, distribution and reproduction for non-commercial purposes, provided the original is properly cited and derivative works building on this content are distributed under the same license. 